\title{
CONSENSO COLOMBIANO DE HEPATITIS C. Conferencias
}

Palabras claves: Consenso Colombiano de Hepatitis C, virus de hepatitis C, Interferón, ribavirina, enzimas hepáticas, hepatitis crónica, hepatocarcinoma, banco de sangre.

\section{Características del virus de la hepatitis C}

Panel de conferencistas

La estructura y mecanismo de replicación del virus de la hepatitis $\mathrm{C}$ (VHC o $\mathrm{HCV}$ ) se conoce en forma incompleta; los estudios in vitro, mediante microscopía electrónica han revelado la envoltura del virus y la microscopía electrónica con inmunoperoxidasa demostró el core y la envoltura proteínica. El VHC está formado por una tira-positiva de RNA rodeada por el core (la nucleocápsula), la cual está rodeada de dos envolturas proteínicas (E1 y E2).

El VHC es una tira simple de RNA de la familia flaviviridae, la cual incluye el virus de la fiebre amarilla y dos virus animales: el virus de la diarrea bovina y el clásico virus de la fiebre porcina.

El genoma del HCV tiene aproximadamente 9000nt y contiene una simple ORF (Marco de Lectura Abierto), capaz de involucrar un polipéptido viral grande precursor de 3.010 a 3.033 aminoácidos. El clivaje de estas estructuras da como resultado una serie de proteínas estructurales y no estructurales; entre las primeras están algunas pertenecientes a la nucleocápside (Cp21) y las envolturas 1 (E1, gp31) y 2 (E2, gp70); entre las segundas están las proteínas NS2, NS3, NS4a, NS4b, NS5a y NS5b. La región estructural NS3 involucra una serina proteasa importante en el clivaje postranslacional de los péptidos virales.

La función de la terminación carboxílica de NS3 como una helicasa es importante durante la replicación viral. Las funciones del NS5A como dependiente de la $A R N$ polimerasa es desconocida pero algunas observaciones indican que tiene un papel importante en la regulación de la replicación de la partícula viral.

La primera división utilizada para describir la heterogenicidad genética se ha llamado genotipo y hace referencia a grupos genéticamente distintos de VHC aislados durante la evolución del virus.

Existen diferentes clasificaciones que originan confusión en los distintos estudios y se ha propuesto una clasificación basada en el análisis filogenético de las secuencias del genoma completo o de regiones subgenómicas.

Hay seis tipos del virus designados en la nomenclatura con números arábigos y los diferentes subtipos se designan con letras minúsculas del abecedario.

El segundo componente de la heterogeneidad genética corresponde a las cuasiespecies, mutaciones ocurridas durante la replicación viral, que permiten la producción de partículas virales, algunas defectuosas y otras no, las cuales están en relación con la respuesta de la inmunidad celular y humoral del huésped.

La distribución de las cuasiespecies del genoma del VHC resulta de: 
- Acumulación de mutaciones en los genomas: que depende de la fidelidad de la RNA polimerasa, la cual cambia de cadenas de un paciente a otro.

- Del nivel de la cinética de la replicación viral: altas replicaciones están asociadas a una mayor acumulación de mutaciones.

- Selección de variables: la cual depende de la tolerancia de la región a las mutaciones que varía de una región genómica a otra.

Tener claridad en el conocimiento del genoma del virus $C$ va a permitir descubrir nuevos esquemas terapéuticos en el futuro, con mejores respuestas des- de el punto de vista del tratamiento virológico, lo que permitirá cambiar la historia natural de la infección por el virus $\mathrm{C}$.

\section{Lecturas recomendadas:}

1.Journal of Viral Hepatitis, 1998; 5 (suppl 1).

2.Gastrointestinal and Liver Diseases, Sleissenger \& Fortran's $6^{\text {th }}$ Edition, Chapter 68, Viral Hepatitis A Through G.

3.Viral Hepatitis Diagnostics, Medizinische Unbiersitätsklinik Freiburg, Germany.

4.Seminars in Liver Disease, 1995; 15 (1).

5.Seminars in Liver Disease, 1999; 19 (suppl 1): 10-11

6.Hepatology, 1998, p.1710 - 1712.

7.Hepatology, 1999; 29 (1): 277-279.

8.Hepatology, 1999; 29 (2): 585-589.

\section{Epidemiología de la Hepatitis C en Latinoamérica y Colombia.}

Fernando de la Hoz R. MD MSc.*

\section{Introducción}

$\mathrm{El}$ virus de la hepatitis $\mathrm{C}(\mathrm{VHC})$ es un agente relacionado genéticamente con los pestivirus, flavivirus y virus de las plantas. Está distribuido alrededor del mundo y su principal forma de transmisión es parenteral, a través de sangre u objetos contaminados por sangre. Más del $80 \%$ de las personas que se infectan con este virus desarrollan un estado de portador crónico después de la infección y un porcentaje apreciable de ellos desarrollarán cirrosis u otras formas graves de enfermedad hepática.

Se estima que alrededor del mundo hay entre 85 y 170 millones de portadores crónicos lo cual representa de $1,5 \%$ a $3 \%$ de la población mundial; ello hace de este virus uno de los principales agentes de enfermedad hepática crónica en todo el mundo.
Los factores de riesgo para la transmisión del VHC han sido estudiados extensivamente en los países desarrollados donde los usuarios de drogas intravenosas son el principal grupo de riesgo, siendo seguidos por los hemofílicos y aquellos otros enfermos que necesitan transfusiones frecuentes. La transmisión sexual aunque sí ocurre, es una fuente mucho menos importante de infección para el VHC que para el virus de la hepatitis B (VHB).

Dado que en Latinoamérica y en Colombia el uso de drogas intravenosas es mucho menos generalizado que en Europa y Norteamérica, es posible que los mecanismos de transmisión tengan un peso diferente entre nosotros, es decir que la frecuencia de transmisión por exposición a drogas IV sea poco importante y que las transfusiones de sangre o las relaciones sexuales promiscuas sean, en cambio, una fuente de contagio más importante.

Con el propósito de aclarar los conocimientos acerca de la epidemiología de la infección por este 
virus en Colombia y Latinoamérica, se realizó una revisión de toda la literatura publicada, que estuviera disponible en la base de datos de LILACS (la base de datos electrónica de la literatura latinoamericana y del Caribe), a través del servidor de BIREME (la biblioteca médica virtual del Brasil y la Organización Panamericana de la Salud). Para Colombia se hizo una revisión manual de las revistas especializadas en el tema, que son básicamente las de la sociedad de Medicina Interna y de la Sociedad de Gastroenterología.

El resultado de esta búsqueda es presentado como la prevalencia de infección en porcentajes para cada uno de los grupos de riesgo, en cada uno de los países y por año de publicación del estudio.

\section{Prevalencia de infección entre los donantes de sangre}

La tabla 1 muestra los resultados de los diferentes estudios en donantes que se han practicado en Latinoamérica y que están registrados en las bases revisadas.

Estos datos muestran que el país con menor prevalencia de positivos en sus donantes es Chile, seguido por Cuba. En el primer estudio Brasil mostró la prevalencia más alta $(2,4 \%)$, mientras que en el segundo estudio ya la prevalencia encontrada es más parecida a la del resto de la región. La mediana de prevalencia de infección en donantes es de 1,0\%,

Tabla I. Prevalencia de infección por el virus de la hepatitis $\mathbf{C}$ en donantes de diferentes países de Latinoamérica.

\begin{tabular}{llcl} 
País & Año & $\begin{array}{c}\text { Número } \\
\text { encuestado }\end{array}$ & Prevalencia \\
\hline Brasil & 19941995 & 2.350966 & $2,2 \% \quad 1,4 \%$ \\
\hline Cuba & 19911995 & 465345 & $1,5 \% 0,6 \%$ \\
\hline Méjico & 1996 & 5.915 & $1,4 \%$ \\
\hline Chile & 1991 & - & $0,2-0,5 \%$ \\
\hline Jamaica & 1995 & 1.500 & $0,4 \%$ \\
\hline Honduras & 1989 & 973 & $0,8 \%$ \\
\hline Colombia & 1992 & 1.033 & $0,97 \%$
\end{tabular}

valor en el cual está Colombia. Brasil, Méjico y Cuba tienen valores por encima de la mediana mientras que Honduras, Jamaica y Chile tienen valores de prevalencia por debajo de esta.

Es importante resaltar que en el estudio de Méjico se estudiaron los resultados para donantes del área urbana y del área rural, sin que se encontraran diferencias significativas en la prevalencia de infección entre las dos áreas (1,34 en el área rural y 1,5\% en el área urbana).

La tabla 2 muestra la prevalencia de infección en los diferentes grupos de personas que por alguna patología de base están expuestas a múltiples transfusiones de sangre en la región. Los grupos más estudiados son los pacientes en hemodiálisis y los hemofílicos; las prevalencias encontradas en 15 estudios revisados en hemodializados oscilan entre $0 \%$ y $65 \%$; sin embargo, la mediana de prevalencia de infección en estos estudios es de 36\%. Los países que tienen prevalencias de infección por debajo de la mediana son Argentina, Méjico, Chile y Venezuela. Por encima de la mediana aparecen Brasil, Colombia, Cuba y Uruguay.

En cuanto a los pacientes con hemofilia, se encontraron cinco estudios, en los cuales la mediana de infección era de $48 \%$; Colombia tenía valores por debajo de la mediana mientras que Brasil, Cuba y Chile tenían prevalencias por encima de ese valor.

Sólo se encontraron en LILACS tres estudios de prevalencia en pacientes transplantados de riñón, donde la prevalencia oscilaba de $0 \%$ a $49 \%$, con una mediana en 21\%. Apenas se encontró un estudio en pacientes con anemia de células falciformes donde la prevalencia era significativamente más baja que en los grupos anteriores (3\%).

\section{Prevalencia en trabajadores de la salud}

Se encontraron nueve estudios en trabajadores de la salud, con una mediana de infección de $2 \%$. Brasil, Colombia y Méjico presentaron prevalencias de infección por encima de la mediana, mientras que 


\begin{tabular}{|c|c|c|c|c|}
\hline País & Año & Tipo de población & No. estudiado & Prevalencia \\
\hline \multirow[t]{5}{*}{ Brasil } & 1992 & Hemodializados & 34 & $23 \%$ \\
\hline & 1993 & Hemodializados & 80 & $50 \%$ \\
\hline & 1995 & Hemodializados & 400 & $48 \%$ \\
\hline & 1997 & Hemodializados & 173 & $35 \%$ \\
\hline & 1998 & Hemofílicos & 62 & $48 \%$ \\
\hline \multirow[t]{2}{*}{ Cuba } & - & Hemofílicos & - & $63 \%$ \\
\hline & - & Hemodializados & - & $60 \%$ \\
\hline \multirow[t]{3}{*}{ Argentina } & 1992 & Hemodializados & 50 & $44 \%$ \\
\hline & 1994 & Hemodializados & 216 & $36 \%$ \\
\hline & 1998 & Hemodializados & 61 & $19 \%$ \\
\hline Méjico & 1997 & Hemodializados & - & $29 \%$ \\
\hline \multirow[t]{4}{*}{ Chile } & 1995 & Hemodializados & 56 & $0 \%$ \\
\hline & 1995 & Hemodializados & - & $60 \%$ \\
\hline & 1995 & Receptores de riñón. & 51 & $0 \%$ \\
\hline & 1990 & Hemofílicos & 25 & $88 \%$ \\
\hline Venezuela & 1990 & Hemodializados & 16 & $33 \%$ \\
\hline Jamaica & 1995 & Anemia falciforme & 250 & $3 \%$ \\
\hline \multirow[t]{2}{*}{ Uruguay } & 1995 & Hemodializados & 78 & $40-65 \%$ \\
\hline & 1995 & Hemodializados & 69 & $3-16 \%$ \\
\hline \multirow[t]{8}{*}{ Colombia } & 1992 & Hemodializados & 45 & $42 \%$ \\
\hline & 1992 & Hemodializados & 192 & $60 \%$ \\
\hline & 1993 & Hemodializados & 75 & $35 \%$ \\
\hline & 1992 & Hemofílicos & 46 & $6.5 \%$ \\
\hline & 1993 & Hemofílicos & 71 & $32 \%$ \\
\hline & 1992 & Transplantados* & 200 & $21 \%$ \\
\hline & 1992 & Transplantados* & 224 & $49 \%$ \\
\hline & 1992 & Politransfundidos & 37 & $13 \%$ \\
\hline
\end{tabular}

Venezuela estaba sobre este valor. Un estudio realizado en Méjico en 1997 mostraba un valor exorbitantemente alto de prevalencia, comparado con lo informado por los otros países; sin embargo, esto puede deberse a defectos en la forma de selección de los participantes (Tabla 3).

\section{Prevalencia de infección en po- blaciones con riesgo incremen- tado de transmisión sexual}

Apenas tres países tienen publicaciones sobre prevalencia del virus de la hepatitis $C$ en personas con riesgo incrementado de transmisión sexual; sólo un estudio es en homosexuales, otro es en trabajadoras sexuales y dos son en pacientes seropositivos para VIH (VIH+).

La prevalencia más alta encontrada en este grupo fue para las personas $\mathrm{VIH}+(35 \%-60 \%)$; sin embargo, es difícil concluir que toda la infección en este grupo es por transmisión sexual dado que otros factores pueden coexistir tales como el abuso de drogas intravenosas.

El estudio en trabajadoras sexuales mostró una prevalencia baja, muy similar a la de los donantes de banco de sangre en Colombia e inferior incluso a 


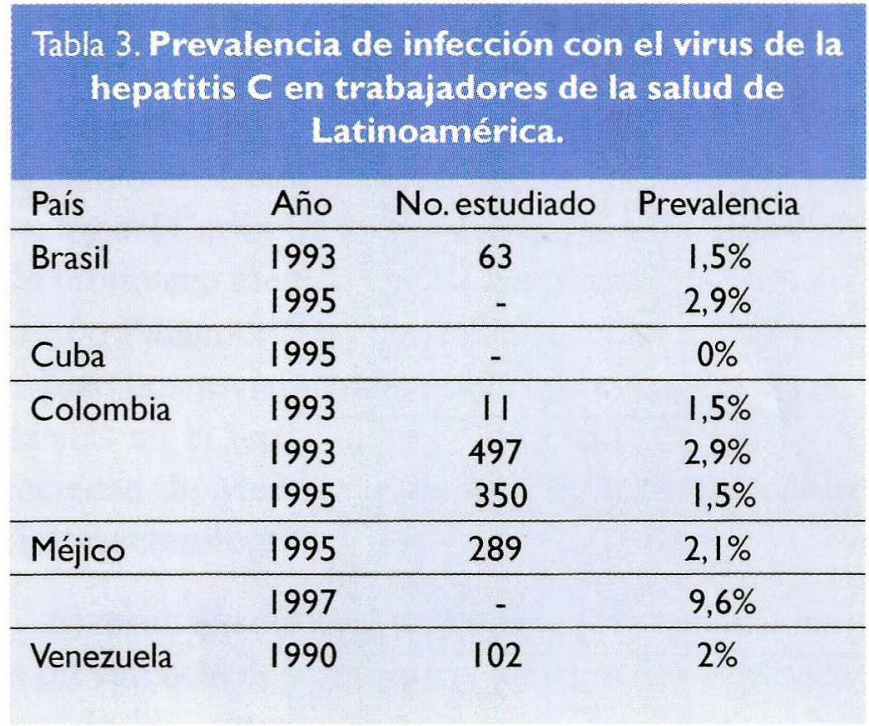

la de los trabajadores de la salud. También es muy baja en los contactos sexuales de pacientes VIH positivos, similar a la de los trabajadores de la salud (Tabla 4).

Sin embargo, dado el pequeño número de estudios publicados, sin duda será necesario realizar más investigaciones poblacionales para dilucidar el papel de la transmisión sexual en la infección por VHC en América Latina.

\section{Prevalencia de la infección por el virus de la hepatitis $\mathbf{C}$ en población general}

Sólo seis estudios fueron encontrados en la base de datos, que tuvieran como objeto de estudio alguna parte de la población general. Como vemos no hay ningún estudio en Colombia y apenas cuatro países de América Latina han publicado tales estudios. El rango de prevalencia de infección va de $0 \%$ a $1,4 \%$, mientras que la mediana se ubica en $1,2 \%$ lo cual es bastante bajo y muy similar a la mediana de los estudios en donantes (Tabla 5).

Uno de los estudios realizados en Brasil, fue hecho en población urbana y rural y se encontró que la prevalencia de infección en la población rural de $0 \%$ mientras que en la zona urbana fue de 1,2\% .
Tabla 4. Prevalencia de infección por el virus de la hepatitis $\mathbf{C}$ en diferentes grupos de personas con riesgo incrementado por transmisión sexual.

\begin{tabular}{lcccc} 
País & Año & $\begin{array}{c}\text { Tipo de } \\
\text { población }\end{array}$ & $\begin{array}{c}\text { No. } \\
\text { encuestado }\end{array}$ & Prevalencia \\
\hline Cuba & 1995 & Homosexuales & - & $4 \%$ \\
\hline & 1995 & $\begin{array}{c}\text { Pacientes VIH+ } \\
\text { Contactos } \\
1995\end{array}$ & - & $60 \%$ \\
& $\begin{array}{c}\text { sexuales de } \\
\text { pacientesVHC+ }\end{array}$ \\
\hline Colombia & 1992 & $\begin{array}{c}\text { Trabajadoras } \\
\text { sexuales }\end{array}$ & 210 & $1 \%$ \\
\hline Venezuela & 1990 & PacientesVIH+ & 20 & $35 \%$ \\
\hline & 1994 & Indigentes & 146 & $4,8 \%$
\end{tabular}

Tabla 5. Prevalencia de infección por el virus de la hepatitis C en segmentos de población general.

\begin{tabular}{lcccc}
\hline País & Año & Población & No. & Prevalencia \\
\hline \multicolumn{5}{c}{ estudiada } \\
encuestado \\
\hline Venezuela 1991 & General & - & $1,2 \%$ \\
& 1993 & General & 200 & $1,5 \%$ \\
\hline Jamaica & 1995 & Embarazadas & 513 & $0 \%$ \\
\hline Brasil & 1994 & General & 460 & $1,4 \%$ \\
& 1995 & General & 800 & $1,2 \%$ \\
\hline Méjico & 1991 & Niños sanos & 450 & $0,9 \%$
\end{tabular}

\section{Prevalencia de infección en pacientes con afecciones hepáticas}

Se encontraron 11 estudios de prevalencia de infección por el virus de la hepatitis $\mathrm{C}$ en pacientes que tenían alguna forma de hepatopatía crónica. La prevalencia fluctuó de $2 \%$ a $35 \%$, con una mediana de $25 \%$. En los casos de hepatitis no A no B, la prevalencia fue de $35 \%$ a $45 \%$, pero sólo se encontraron tres estudios, lo que indica la pobreza de la vigilancia en América Latina sobre la etiología de los episodios agudos de ictericia (Tabla 6).

Llama la atención la prevalencia de infección tan baja que se encontró en pacientes con cirrosis alcohólica en Brasil y Chile. Es interesante mencionar 
Tahla 6. Prevalencia de infección por el virus de la hepatitis C en pacientes con alguna forma de enfermedad hepática.

\begin{tabular}{lcccc} 
País & Año & $\begin{array}{c}\text { Tipo de } \\
\text { enfermedad }\end{array}$ & No. estudiado & Prevalencia \\
\hline Brasil & 1999 & Cirrosis alcohólica & 50 & $4 \%$ \\
\hline Cuba & 1995 & Pacientes con ALT elevadas & - & $12 \%$ \\
\hline Colombia & 1992 & Hepatopatías crónicas. & 45 & $31 \%$ \\
\hline Chile & 1995 & Cirróticos & 424 & $22 \%$ \\
& 1995 & Hepatitis no A no B & - & $45 \%$ \\
\hline Argentina & 1991 & Hepatitis crónica & 94 & $35 \%$ \\
& 1991 & Hepatitis crónica & 39 & $38 \%$ \\
& 1991 & Hepatitis crónica & 37 & $22 \%$ \\
& 1987 & Hepatitis agudano A no B & - & $37 \%$ \\
& 1991 & Cirrosis biliar & 31 & $3.2 \%$ \\
\hline Méjico & 1991 & Colestasis & 6 & 33 \\
\hline Sin dato & 1997 & Cirrosis & 157 & $25 \%$ \\
\hline & 1992 & Hepatitis no A no B & 40 & $35 \%$
\end{tabular}

$22 \%$ no tenían cambios que indicaran cronicidad. En el mismo año fueron estudiados 248 donantes que eran VHC positivos por ELISA, de los cuales $53 \%$ se encontraron positivos para ARN VHC.

\section{Estudios de factores de riesgo}

Se encontraron seis estudios de tipo analítico que buscaban encontrar factores que explicaran la positividad al VHC en América Latina. Los factores de riesgo más fuertes encontrados en los estudios eran los relacionados con exposición parenteral, drogadicción intravenosa y transfu-

que en Brasil se estudiaron simultáneamente 315 pacientes alcohólicos sin cirrosis y la prevalencia encontrada fue de $0,4 \%$, diez veces menor que en los pacientes alcohólicos con cirrosis, lo cual sugiere que aún en los casos de hepatitis supuestamente alcohólica el VHC puede jugar un papel etiológico, aunque en menor proporción que en otros cuadros.

\section{Estudios que muestran el significado de la positividad a VHC en América Latina}

Se encontraron tres estudios publicados en Brasil y Argentina que buscaban mirar el significado de la positividad al VHC, desde el punto de vista virológico o histopatológico. En Brasil se estudiaron 46 donantes $\mathrm{VHC}+$ con técnicas de PCR para detectar RNA viral en 1996; de estos pacientes $48 \%$ era positivo para ARN del VHC, o sea que el valor predictivo de la prueba ELISA para detectar pacientes con infección activa es inferior a 50\%.

En 1997 en la Argentina se realizó un estudio con 54 pacientes $\mathrm{VHC}+$ a quienes se les practicó biopsia hepática. De ellos, 70\% tenían signos histopatológicos de hepatitis crónica, mientras que sólo siones. Este último fue encontrado significativamente asociado con la infección en tres de los estudios, especialmente en los dos estudios de casos y controles, que son más adecuados para la prueba de hipótesis de asociación que los estudios transversales.

Las intervenciones quirúrgicas fueron encontradas asociadas en dos de los estudios, incluyendo uno de casos y controles y lo mismo ocurrió con la promiscuidad; sin embargo, en uno de los estudios esta asociación era sólo marginal (Tabla 7).

\section{Conclusiones}

El mayor numero de estudios realizados y publicados en América Latina ha tenido como objetivo medir la prevalencia de infección en personas sometidas a múltiples transfusiones, tales como hemofílicos y hemodializados. La prevalencia encontrada en estas poblaciones es la más alta de todas las poblaciones estudiadas, lo que refuerza el hecho de que las transfusiones son la vía por la cual se ha adquirido la mayoría de las infecciones en la población. Esto es muy importante porque dado que en los bancos de sangre está incluido el tamizaje para 


\title{
Epidemiología de la hepatitis C. Bancos de sangre
}

\author{
Mauricio Beltrán Durán*
}

El desarrollo de la red nacional de bancos de sangre con base en 95\% de los bancos dentro de los hospitales que colectan $80 \%$ de la sangre, ha llevado a que la donación de sangre se convierta en obligatoria por reposición o mal llamada intrafamiliar, haciendo que estas personas donen, en su mayoría solamente una vez.

Esta sangre captada de población general y no de población repetitiva y seleccionada, proviene de individuos con un numero mayor de factores de riesgo para la presencia de infecciones que pueden ser transmitidas por la sangre, como lo demuestran el hallazgo de elevados porcentajes de serorreactividad de estas infecciones, llevando finalmente a un aumento del riesgo de transmisión de estas infecciones por la vía transfusional.

La seroprevalencia estimada en donantes para los diferentes marcadores infecciosos, es de aproximadamente, tres por cada mil para marcadores como VIH y entre 8 y 10 unidades de cada 1.000 para los demás; estas prevalencias distan de las observadas en otros países con mejores mecanismos de selección de donantes y procesamiento de los productos sanguíneos como Inglaterra y Estados Unidos.

El virus de la hepatitis C (VHC) es el responsable de la mayoría de las hepatitis postransfusionales. Otros mecanismos de transmisión aunque menos probables son la transmisión sexual y la vertical de madre-hijo la cual tiene mayor importancia si la madre adquiere la infección en el tercer trimestre de embarazo aumentando el riesgo de contagio para el recién nacido. Los grupos de mayor riesgo son los pacientes hemofílicos, drogadictos endovenosos y hemodializados. La hepatitis $\mathrm{C}$ ha disminuido con

Bacteriólogo - Epidemiólogo de campo. CDC - INS - SEA la determinación rutinaria del anticuerpo anti-VHC en donantes de sangre.

Se han descrito varios genotipos del VHC y la utilidad de la clasificación de los genotipos radica en la variación del grado de infectividad, patogenicidad y grado de respuesta al interferón. Se estima que más de $50 \%$ de los individuos infectados con el VHC desarrollará una hepatitis crónica y de estos cerca de 5\% progresan a hepatocarcinoma celular.

Se ha comprobado que el VHC, es un virus altamente persistente y de tratamiento difícil. Aproximadamente la mitad de las personas con infección VHC crónica no presenta niveles elevados de enzimas hepáticas y muchos de los pacientes no experimentan síntomas o éstos son mínimos; sin embargo pueden tener un daño hepático significativo. No existe un progreso estándar de la enfermedad con respecto a la infección del VHC y es difícil establecer un pronóstico definitivo. Los reportes indican que el daño hepático puede ser significativo en un lapso de diez años y puede progresar a cirrosis (desarrollo de tejido de cicatriz que inhibe la función hepática en veinte años).

Estudios basados en anticuerpos anti-VHC estiman que $1 \%$ de la población mundial se encuentra infectada con el virus de la hepatitis $\mathrm{C}$, con variaciones geográficas, por ejemplo, en Norte América es de 1,1.\%, en América Central de $0,4 \%$ y en Sur América de 2,6 a 2,9\%.

La seroprevalencia notificada para 1996 en donantes de sangre varía desde 6 por cada 10.000 unidades de sangre donadas, en Inglaterra, hasta 145 por cada 10000 unidades en países como México (Tabla 8). 


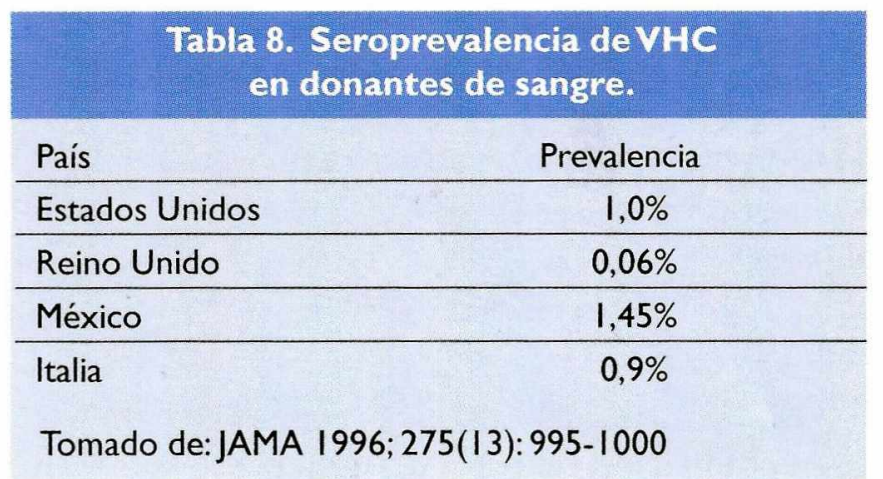

Los primeros estudios realizados en Colombia mostraron que $69 \%$ de los casos positivos para hepatitis $\mathrm{C}$ tenían antecedentes de transfusión como principal mecanismo de exposición al virus, situación que se mantiene tal como lo demostró recientemente un estudio donde se halló que 76\% de los casos de hepatitis $\mathrm{C}$ tenían este antecedente y de los cuales 38\% habían sido donantes de sangre.

En Colombia la prueba de detección de anticuerpos contra el virus de hepatitis $\mathrm{C}$ se introdujo en 1993 y para este año se halló una prevalencia de 100 por cada 10.000 unidades en donantes de sangre. Para los años siguientes la prevalencia en donantes de sangre se ha mantenido entre 70 y 100 unidades por cada 10.000 unidades de sangre. hepatitis C tenían antecedentes de transfusión como principal mecanismo de exposición al virus, situación que se mantiene tal como lo demostró recientemente un estudio donde se halló que $76 \%$ de los casos de hepatitis C tenían este antecedente y $38 \%$ habían sido donantes de sangre.

En estudio reciente muestra que para el período de 1993 a 1996 los bancos de sangre recolectaron un total de 2'270.236 unidades de sangre, y analizaron para anticuerpos antivirus de hepatitis $\mathrm{C}$ 1'976.732 (87\%) de estas, 16706 unidades de sangre fueron doblemente serorreactivas para anticuerpos antivirus de hepatitis $\mathrm{C}$, lo que podría indicar que igual número de individuos fue detectado como infectado con virus de hepatitis $\mathrm{C}$ a través del tamizaje en bancos de sangre.

La prevalencia en donantes de sangre se ha mantenido entre 70 y 100 unidades por cada 10.000 unidades de sangre, para estos años (Gráfica 1).

Este estudio además informó que el número estimado de individuos que podrían haber sido infectados por no ser tamizadas el total de unidades de sangre obtenidas en los bancos de sangre del país, para ese periodo, fue superior a 1900 individuos, teniendo en cuenta la seroprevalencia hallada, el porcen-

El tamizaje serológico entre los donantes de sangre, ha permitido disminuir la transmisión de esta enfermedad; por ello, los donantes de sangre con resultados doblemente serorreactivos a las pruebas de tamizaje o donantes de riesgo son individuos seleccionados y candidatos muy probables a presentar este tipo de infección, por lo cual, los datos de donantes podrían utilizarse para determinar la existencia de zonas endémicas para hepatitis $C$.

Los primeros estudios realizados en Colombia mostraron que $69 \%$ de los casos positivos para

\section{Gráfica 1. Porcentaje de reactividad para VHC en donantes de sangre de Colombia 1993-1998}

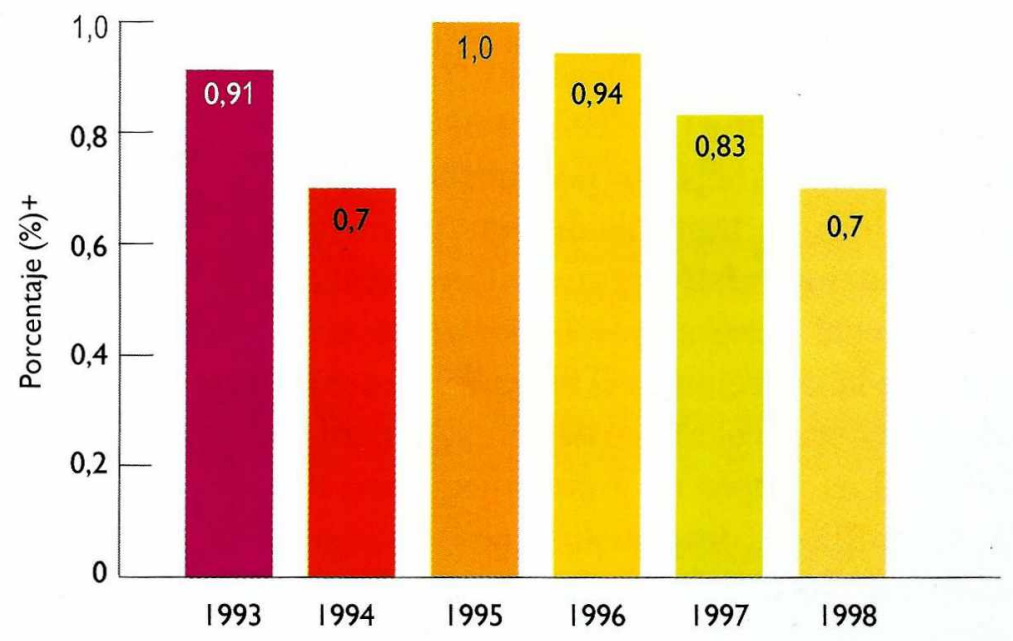


taje de infectividad de $75 \%$ para VHC que reporta la literatura y la cobertura serológica de tamizaje.

Sin embargo, los datos son sólo un estimativo ya que no se tuvieron en cuenta los valores predictivos de las pruebas realizadas y tampoco se consideró que una unidad de sangre infectada al fraccionarse podría ser transfundida a más de un individuo o simplemente no ser transfundida. Los departamentos de Chocó, Guaviare Arauca, Guainía y Amazonas, han presentado valores de reactividad para anticuerpos anti-VHC más altos, con valores que oscilan entre $1,3 \%$ y $18,5 \%$.
Dado que la población de donantes de sangre es, generalmente, asintomática y de bajo riesgo son las prevalencias halladas para anticuerpos anti-VHC, es necesario definir la condición clínica real de estos individuos $\mathrm{y}$, de esta manera, disminuir el impacto de esta enfermedad en la población colombiana.

Además, estos datos muestran cómo los bancos de sangre pueden servir de unidades de vigilancia de enfermedades en donantes de sangre como hepatitis $\mathrm{C}$ en población de bajo riesgo o no sintomática que requiere ser evaluada clínica y serológicamente para establecer su diagnóstico real.

\section{Historia natural, manifestaciones clínicas y diagnóstico de la hepatitis $\mathrm{C}$}

Victor Idrovo C. M.D.*

El curso clínico de la hepatitis $\mathrm{C}$ ha sido difícil de establecer ya que la hepatitis aguda rara vez es identificada y la evolución de la enfermedad hepática crónica hasta su descompensación toma varias décadas. Ante la presencia de un caso de hepatitis $\mathrm{C}$, es importante determinar si hay algún factor de riesgo presente o si el desarrollo de la infección ha sido de manera esporádica. Antes de 1990 cuando no existían las pruebas serológicas para la detección de anticuerpos contra hepatitis $\mathrm{C}$, la transfusión de productos sanguíneos contaminados era el principal factor de riesgo asociado a esta infección.

Desde 1990 hasta la actualidad, la drogadicción intravenosa se ha convertido en el principal factor de transmisión del virus de la hepatitis C. En menor proporción se han descrito casos asociados con diálisis y en trabajadores de la salud. Aunque la transmisión sexual es probable, esta usualmente no se presenta en parejas estables y sí en poblaciones promiscuas. Independientemente del factor de riesgo

\footnotetext{
Hepatólogo Clínica de Marly y Fundación Santafé, Bogotá, D.C.
}

presente o no, una vez se presente la infección por el virus de la hepatitis $C$, su curso puede ser variable debido a algunos factores asociados que se describirán más adelante.

La presentảción inicial es la hepatitis aguda. Su periodo de incubación promedio es de siete semanas (rango 3-20 semanas). Se presenta elevación de la alaninoaminotransferasa (ALT), y la positividad para el anticuerpo contra el virus de la hepatitis $\mathrm{C}$ (Anti HCV) se presenta a veces en forma tardía (hasta la semana 15 de infección). La determinación de la viremia por biología molecular (PCR o bDNA) es posible desde la segunda semana de la infección.

La hepatitis $\mathrm{C}$ aguda generalmente es asintomática (hasta $70 \%$ de los casos). Menos de $30 \%$ pueden presentar el cuadro clásico de ictericia, coluria, hiporexia y síntomas de estado gripal (flu-like) que pueden confundir el diagnóstico con otro estado viral transitorio. La falla hepática fulminante es prácticamente inexistente en la hepatitis C. Todos los casos de hepatitis $\mathrm{C}$ tienen un curso clínico agudo, gene- 
ralmente sin ninguna sintomatología, por lo cual su detección es rara. De todos los casos agudos, 15\% se autolimitan entre 2 y 12 semanas con normalización de la ALT y negativización del RNA del virus $\mathrm{C}$, en las técnicas de biología molecular.

Alrededor de $85 \%$ de las infecciones agudas se vuelven crónicas (más de seis meses). Aproximadamente un 30\% de los infectados crónicos se vuelven portadores asintomáticos, con un ALT persistentemente normal pero con una determinación de RNA del virus $\mathrm{C}$ positivo. La biopsia hepática en estos casos, muestra cambios mínimos de inflamación y de fibrosis. La mortalidad usualmente es por causas no hepáticas; por lo cual hoy se considera que no es necesario el tratamiento en este grupo de sujetos.

De los infectados crónicos $70 \%$ desarrollan hepatitis crónica con persistencia de viremia positiva y elevación de aminotransferasas, la cual es fluctuante y a veces dentro de límites normales. La hepatitis crónica por virus $\mathrm{C}$ es una enfermedad progresiva de evolución variable, que generalmente toma varias décadas para el desarrollo de enfermedad hepática avanzada. El espectro de su evolución es muy amplio, teniendo $80 \%$ de casos de evolución muy lenta con una mortalidad generalmente por causas no hepáticas. Tan sólo $20 \%$ de casos de hepatitis C crónica progresa hasta cirrosis con o sin hepatocarcinoma y la mortalidad es debida, básicamente, por insuficiencia hepática o por enfermedad maligna si no se efectuó el trasplante hepático.

La investigación de la historia natural de la hepatitis $\mathrm{C}$ crónica ha demostrado que desde el inicio de la infección hasta el desarrollo de hepatitis crónica leve se toman 10 años; hasta hepatitis crónica severa 18 años; hasta cirrosis 22 años, y hasta hepatocarcinoma 30 años. Es fundamental la presencia de cirrosis para la aparición de hepatocarcinoma en la hepatitis $\mathrm{C}$, a diferencia del hepatocarcinoma en hepatitis $\mathrm{B}$, que se puede presentar en ausencia de cirrosis (Gráfica 2).
Hay múltiples factores contribuyentes para que la evolución de la hepatitis C crónica sea variable. Estos factores de una u otra manera pueden favorecer para que en algunos infectados por hepatitis $\mathrm{C}$ la enfermedad tenga un curso benigno e incluso ocurra la muerte por causas distintas a la afección hepática. Por otra parte, estos factores también pueden ser responsables de que el curso de la infección sea más agresivo, con el desarrollo de enfermedad hepática severa (cirrosis, hepatocarcinoma).

Hay tres grupos de factores responsables para esta variabilidad: del virus, del hospedero y otros adicionales.

Con respecto al virus, la carga viral elevada, el genotipo 1 y la presencia de cuasiespecies favorecen el desarrollo de enfermedad hepática de más rápida evolución y mayor severidad. En el hospedero, los factores negativos que contribuyen a la progresión de la hepatitis $\mathrm{C}$ son una edad mayor de 40 años, sexo masculino y raza distinta a la caucásica.

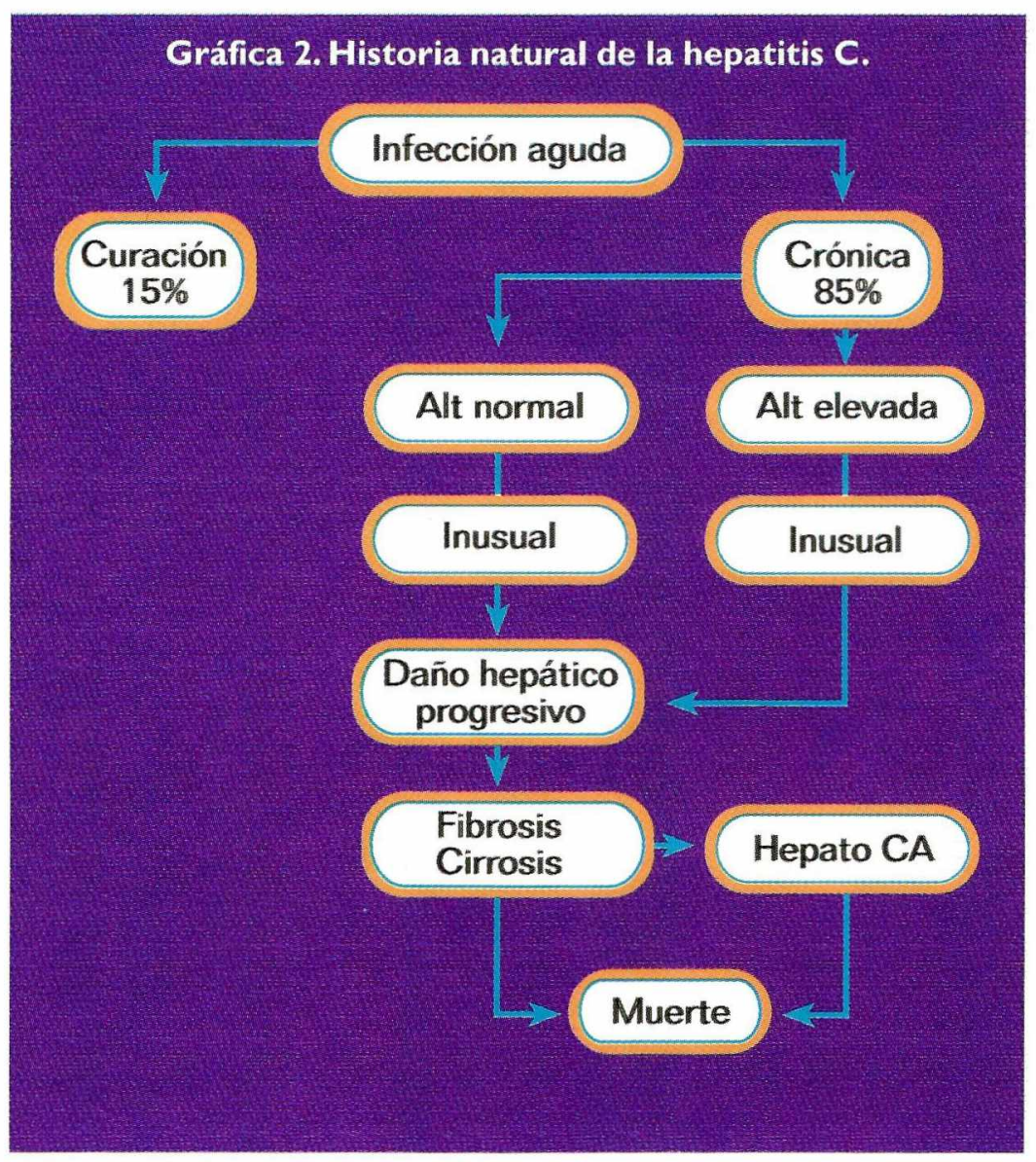


Otros factores perjudiciales para la evolución de la hepatitis C crónica, y ampliamente descritos en la literatura, son el alcoholismo y la coinfección viral. La ingesta de alcohol en un paciente con hepatitis $\mathrm{C}$ crónica acelera el proceso de fibrosis y el desarrollo de cirrosis con o sin hepatocarcinoma. Por esto, la abstinencia de alcohol es fundamental en el tratamiento de tales pacientes. La coinfección por virus A y B de la hepatitis puede favorecer el desarrollo de falla hepática fulminante y la coinfección por VIH acelera el proceso de enfermedad hepática crónica avanzada. Se recomienda la vacunación contra hepatitis $\mathrm{A}$ y $\mathrm{B}$ en los pacientes, con hepatitis $\mathrm{C}$, que no han tenido contacto previo con estos virus.

La hepatitis C crónica es un hallazgo incidental en pacientes asintomáticos que, en donación de sangre o en chequeos de rutina, presentan anticuerpos contra el virus $\mathrm{C}$ o aminotransferasas elevadas. Cuando se presentan síntomas, lo más frecuente es la fatigabilidad y el cansancio cuya etiología no está muy clara.

Ocasionalmente se presentan pacientes con enfermedad hepática terminal, con estigmas clásicos de hepatopatía crónica: telangiectasias en araña, eritema palmar, pérdida del vello púbico y axilar, ginecomastia, atrofia testicular, ascitis e ictericia. Rara vez se presentan manifestaciones extrahepáticas asociadas a la hepatitis $\mathrm{C}$ crónica; las más frecuentes son crioglobulinemia mixta, glomerulonefritis, síndrome sicca, vasculitis, eritema nodoso, liquen plano y porfíria cutánea tarda. Estos hallazgos son importantes ya que pueden tener implicaciones en el tratamiento a seguir.

La presentación de la hepatitis C es muy variable y se debe individualizar cada caso para tomar la decisión terapéutica adecuada y establecer un pronóstico lo más cercano a la realidad.

El diagnóstico de hepatitis $\mathrm{C}$ comprende cuatro grupos básicos:

1.Diagnóstico clínico-bioquímico.

2.Diagnóstico serológico.

3.Diagnóstico virológico por biología molecular. 4.Diagnóstico histopatológico.
Diagnóstico clínico-bioquímico: es bastante inespecífico ya que por lo general no hay síntomas ni signos presentes. Desde el punto de vista bioquímico es usual encontrar elevación fluctuante de las aminotransferasas por un tiempo superior a los 6 meses.

Diagnóstico serológico: las pruebas de ELISA de segunda y tercera generación han logrado aumentar considerablemente la sensibilidad y especificidad en el diagnóstico de la hepatitis C, debido a la detección de un grupo mayor de anticuerpos contra antígenos recombinantes específicos para este virus. El RIBA II y III es útil para confirmar si la prueba de ELISA es verdadera positiva o no, pero no puede determinar si el paciente está infectado o se curó.

Se presentan dos grandes grupos de sujetos. El primer grupo lo constituyen aquellos con factor de riesgo positivo y/o elevación de aminotransferasas. En este grupo, un ELISA II-III positivo para AntiHepatitis C tiene una sensibilidad y especificidad cercanas a 95\%. No será necesario confirmar con RIBA y se deberá proceder a la determinación de la viremia o carga viral si se va a contemplar tratamiento.

El segundo grupo lo conforman personas generalmente donantes, sin factores de riesgo y con aminotransferasas normales; un ELISA II-III positivo en este grupo presenta una especificidad baja, cercana a 50\% para diagnóstico de Hepatitis C. En estos casos es preciso realizar un RIBA II-III que si reporta un resultado positivo se considera un verdadero positivo para Virus C y se deberá realizar, a continuación, una viremia mediante PCR cualitativo para determinar si el sujeto se curó de la infección o es un portador del virus. Un RIBA II-III negativo descarta la infección por virus de la hepatitis C.

\section{Diagnóstico virológico por biología molecular:} hay dos técnicas estandarizadas para la determinación de la viremia y la carga viral de la hepatitis C, son la reacción en cadena de la polimerasa (PCR) y la técnica de DNA ramificado (bDNA). La prueba de PCR tiene la ventaja de ser cualitativa o cuantitativa y detecta niveles bajos de RNA del virus C. El bDNA es una técnica cuantitativa que tiene los be- 
neficios de ser altamente reproducible y no está sujeta al riesgo de contaminación de la muestra. Sin embargo, el bDNA no llega a niveles de detección del RNA del virus $\mathrm{C}$ tan bajos como el PCR. Cualquiera que sea la técnica que se use, en general, las pruebas cualitativas de la viremia son útiles para confirmar un diagnóstico de hepatitis C como se mencionó anteriormente y para el seguimiento durante y después del tratamiento. Las pruebas cuantitativas son útiles para determinar la carga viral antes del tratamiento como pronosticador importante de respuesta al mismo.

Otras técnicas de biología molecular útiles en hepatitis C son aquellas que determinan el genotipo. No están disponibles comercialmente pero son importantes como predictores de respuesta al tratamiento para la hepatitis $\mathrm{C}$, sabiéndose que el genotipo 1 es el menos favorable para el tratamiento y el que más se asocia a enfermedad hepática severa. También se han desarrollado pruebas serológicas (SIA-RIBA) que permiten identificar los serotipos 1, 2, y 3 del virus $C$. Es posible que la determinación de serotipos llegue a estar disponible comercialmente en el futuro próximo.

Diagnóstico histopatológico: La biopsia hepática, finalmente determina, la evolución crónica de la hepatitis $\mathrm{C}$ y es el principal factor pronóstico para establecer la historia natural de la enfermedad en un paciente; además, es un predictor importante de la respuesta al tratamiento.

\section{Lecturas recomendadas}

1. Alter H. Natural history and clinical aspects of hepatitis C virus infection. In Schinazi, Sommadossi, Thomas, Therapies for Viral Hepatitis. International Medical Press, $1^{\text {st }}$ edition. Pg: 43-50. 1998

2. Wilber J. New development in hepatitis $\mathrm{C}$ diagnostics and monitoring. en: Schinazi, Sommadossi, Thomas Therapies for Viral Hepatitis. International Medical Press, $1^{\text {st }}$ edition. Pg: 133138. 1998

3. Alter MJ, Margolis HS, Krawczynski K, et al. The natural history of community-acquired hepatitis $\mathrm{C}$ in the U.S. N. Engl J Med. 1992; 327: 1899-1905.

4. Seeff LB, Buskell-Bales Z, Wright EC, et al. Long-term mortality after transfusion- associated non A, non B hepatitis. N Engl J Med. 1992. 327:1906-1911.

5. Poynard T, Bedossa P, Opoler P. Natural history of liver fibrosis progression in patients with chronic hepatitis $\mathrm{C}$. Lancet. 1997; 349:825-832.

6. Tong MJ, el-Farra NS, Reikes AR, et al. Clinical outcomes after transfusion-associated hepatitis C. N Engl J Med. 1995; 332:1463-1466.

7. Younossi Z, Mc Hutchinson J. Serological tests for HCV infection. Viral Hepatitis Reviews. 1996; 2:161-173.

8. Fattovich G, Giusting G, Degos F, et al. Morbidity and mortality in compensated cirrhosis type C. Gastroenterology. 1997; 112:463-472.

9. Foster GR, Goldin RD, Thomas HC. Chronic hepatitis C virus infection causes a separate reduction in quality of life in the absence of cirrhosis. Hepatology. 1998; 27: 209-212.

10. Shiffman ML. Management of hepatitis C. Clinical perspectives in Gastroenterology. 1998; 5: 6-19.

\section{Hepatitis C: estándares de tratamiento}

Rafael Claudino Botero. M.D.*

\section{Justificación del tratamiento}

El virus de la Hepatitis C (VHC) descubierto hace 10 años es responsable de importante morbi-mortalidad en Colombia y en el mundo. Se acepta que existen más de 100'000.000 de personas infectadas en todo el planeta, y 4'000.000 de personas en los

* Profesor Asistente Universidad El Bosque. Servicio de Gastroenterología y Hepatología, Departamento de Medicina Interna, Fundación Santafé de Bogotá.
Estados Unidos. En Colombia cerca de $1 \%$ de los donantes voluntarios de sangre son positivos para el anti-HCV, y se estima que en la población general esta cifra debe ascender a 3\%-4\%.

Las razones más importantes por las cuales está claramente justificada la intervención terapéutica se mencionan a continuación:

- De $20 \%$ a $30 \%$ de los pacientes infectados se encuentran en riesgo de desarrollar cirrosis y 
hepatocarcinoma a corto y largo plazo, dependiendo de la duración de la infección.

- La falla hepática crónica es consecuencia frecuente de la infección crónica por el VHC.

- La cirrosis hepática por el VHC, con todas sus complicaciones asociadas, es la indicación más frecuente para el trasplante hepático en el mundo y en Colombia.

- La enfermedad hepática crónica secundaria al VHC es la segunda causa más frecuente de muerte en los pacientes con transplante renal.

- Aunque existe poca evidencia que pueda predecir a largo plazo los benefícios de la intervención terapéutica, la evidencia a corto y mediano plazo sí la justifica.

- Recientes estudios muestran el costo/beneficio del tratamiento comparado con el manejo tradicional y, así mismo, un cambio favorable en la calidad de vida, los costos y los años de vida ganados en los pacientes tratados exitosamente.

\section{Estándares de tratamiento}

Con base en los consensos sobre hepatitis $\mathrm{C}$ realizados en Estados Unidos, Italia, Alemania y Francia y también de los estudios multicéntricos controlados, efectuados recientemente en los Estados Unidos y Europa, se hacen las siguientes recomendaciones relacionadas con el manejo y el tratamiento de los pacientes.

\section{Consenso del NIH}

El consenso del NIH en los Estados Unidos en 1997 ha identificado algunos factores predictivos de respuesta al tratamiento con interferón, de los cuales los más importantes son:

1. Carga viral: cifras inferiores a 2 millones de copias/mL se asocian con respuesta favorable a la monoterapia o a la terapia combinada. La desaparición del ARN del VHC a las 12 semanas de tratamiento es un factor predictivo de respuesta al tratamiento con monoterapia.
2. Genotipo: el genotipo 1 de mayor prevalencia en los Estados Unidos y en Colombia, se asocia con un menor porcentaje de respuesta al tratamiento, por lo cual es necesario prolongar la monoterapia o la terapia combinada por $12-18$ meses.

3. Fibrosis y cirrosis: la presencia de inflamación significativa y de necrosis de interfase y fibrosis indica posible progresión a cirrosis en más de $70 \%$ de los pacientes y menor respuesta al tratamiento. En el mismo sentido una biopsia hepática normal o con mínima inflamación representa un riesgo muy bajo de progresión a la cirrosis $(<7 \%)$ y poca respuesta al tratamiento. Por ello, es muy importante realizar la biopsia hepática antes de iniciar el tratamiento.

Una vez diagnosticada la hepatitis $\mathrm{C}$, y con miras a un tratamiento con buenas posibilidades de éxito, se debe recomendar a todos los pacientes las siguientes pruebas:

- Confirmación de la positividad del anti-HVC con un ARN-VHC cualitativo

- Carga viral

- Genotipo vs. serotipo

- Biopsia hepática

Si bien en los estudios iniciales de monoterapia con interferón el éxito del tratamiento se medía con base en la normalización de la ALT, los estudios recientes de terapia combinada han definido 2 tipos de respuestas que deben claramente entenderse para poder interpretar adecuadamente los resultados:

- Respuesta al final del tratamiento: normalización de la ALT y el ARN-VHC al finalizar el tratamiento.

- Respuesta sostenida: normalización de la ALT y el ARN-VHC seis meses después de terminar el tratamiento.

Desde hace casi 20 años se ha reconocido el efecto benéfico de los interferones en el tratamiento de las hepatitis $\mathrm{B}$ y C, y por ello vienen estudiándose en forma extensa. Los interferones son sustancias con efectos anti virales e inmunomoduladores cuya ac- 
ción principal se basa en el bloqueo de la replicación viral en la célula hepática y paralelamente potencian la depuración del virus por el sistema inmune del hospedero. Hasta época reciente la monoterapia con los interferones alfa era la terapia estándar para el tratamiento de las infecciones por el VHC. En la mayoría de los países del mundo han sido aprobados los siguientes interferones recombinantes alfa:

- Interferón alfa-2b (INTRON A, Sheringh-Plough).

- Interferón alfa-2a(ROFERON-A, Hoffman-La Roche).

- Interferón alfacon-1 (INFERGEN, Amgen Inc).

- Interferón ala-1n (WELLFERON, Glaxo, Wellcome).

Estos cuatro interferones son equivalentes en cuanto a su efectividad clínica. Múltiples estudios en Europa y los Estados Unidos han mostrado que la monoterapia con cualquiera de estos normaliza la ALT y negativiza el ARN-VHC al finalizar el tratamiento en $40 \%$ de los pacientes. Sin embargo, cerca de la mitad de estos recaen al terminar el tratamiento y sólo $10 \%$ a $20 \%$ de ellos muestran una respuesta sostenida duradera al final del seguimiento.

Dada la gran frecuencia de cronicidad de este agente, está claramente justificado iniciar tratamiento con interferón una vez se establęzca el diagnóstico de hepatitis $\mathrm{C}$ aguda. Los estudios de Lampertigo y Hwang han mostrado porcentajes de respuesta de cerca de $40 \%$, con desaparición del ARN-HCV en forma definitiva.

Como consecuencia de este bajo porcentaje, se han hecho múltiples intentos para mejorar la respuesta sostenida al tratamiento, incluyendo la administración de dosis diarias, pues el virus tiene una vida media corta (tres horas), que le confiere ventajas replicativas en los días intermedios sin terapia.

Así mismo, el uso de dosis más altas o la combinación del interferón con agentes antivirales como la ribavirina, permite duplicar los porcentajes de respuesta sostenida y al final del tratamiento. La utilización de la ribavirina partió de la buena experien- cia obtenida con el uso de múltiples agentes antivirales en el tratamiento de los pacientes con infección por el VIH.

La ribavirina (1-B-D-ribofuranosil-1,2,4 triazolecarboxamida, REBETOL $®$, Shering-Plough) es un nucleósido de estructura similar a la azatioprina que puede utilizarse por vía oral y es efectiva contra algunos virus ARN y ADN. En Colombia existió hasta hace poco para el tratamiento de las infecciones infantiles por el virus respiratorio sincicial

El mecanismo de acción más probable de este medicamento implica la depleción de los depósitos intracelulares de trifosfatos, la inhibición del ARN mensajero y de la polimerasa de ARN del virus; así mismo, puede tener acción inmunomoduladora. El principal efecto en la práctica clínica es evitar las recaídas cuando se emplea en asociación con los interferones y en monoterapia puede reducir temporalmente la ALT pero no ejerce ningún efecto sobre el ARN-VHC viral.

\section{Tratamiento de pacientes con Hepatitis C Crónica nuevos o de recaída}

Los estudios iniciales han mostrado claramente que la combinación de interferones alfa y ribavirina puede obtener unos porcentajes de respuesta sostenida que fluctúan entre $30 \%$ y $70 \%$, según la carga y el genotipo viral. Estudios recientes controlados y aleatorizados, llevados a cabo en Europa y los Estados Unidos por Reichard, Poynard, Davis y Mc Hutchinson, reportaron diferencias significativas, cuando se compara el tratamiento combinado con la monoterapia con interferón en grupos de pacientes nuevos y/o con recaídas en tratamientos previos. Estos estudios lograron en 1998 la aprobación por la FDA en los Estados Unidos para terapia combinada en pacientes nuevos y/o de recaída.

En pacientes nuevos (naive), Davis y colaboradores, utilizando terapia combinada lograron obtener una respuesta completa al final del tratamiento en $82 \%$ de los pacientes, comparada con sólo $47 \%$ en aquellos manejados con monoterapia $(p<0,001)$. 
De igual modo, en los pacientes evaluados seis meses después de terminar el tratamiento (respuesta sostenida), la combinación obtuvo un porcentaje de respuesta de $49 \%$, en comparación con sólo $5 \%$ en el grupo de monoterapia $(\mathrm{p}<0,001)$ (Gráfica 3).

Estos mismos resultados se repitieron en el grupo de pacientes que habían recaído después de monoterapia inicial, ya que McHutchison y colaboradores obtuvieron una respuesta sostenida de $33 \%$ y $41 \%$ a las 24 y 48 semanas de terapia combinada, en comparación con sólo $6 \%$ y $16 \%$ con monoterapia, respectivamente. Además, registraron una significativa mejoría en los índices de actividad inflamatoria histológica en los casos con respuesta sostenida, de acuerdo a la clasificación de Knodell (Gráfica 4).

Más recientemente se ha podido demostrar una clara relación entre la respuesta sostenida al tratamiento y la mejoría de la calidad de vida de los pacientes tratados exitosamente.

Estos estudios han permitido, además, demostrar la relación costo/beneficio cuando se utiliza la carga viral y el genotipo antes de iniciar el tratamiento, ya

\section{Gráfica 3. Hepatitis C crónica}

(\%) Resp.

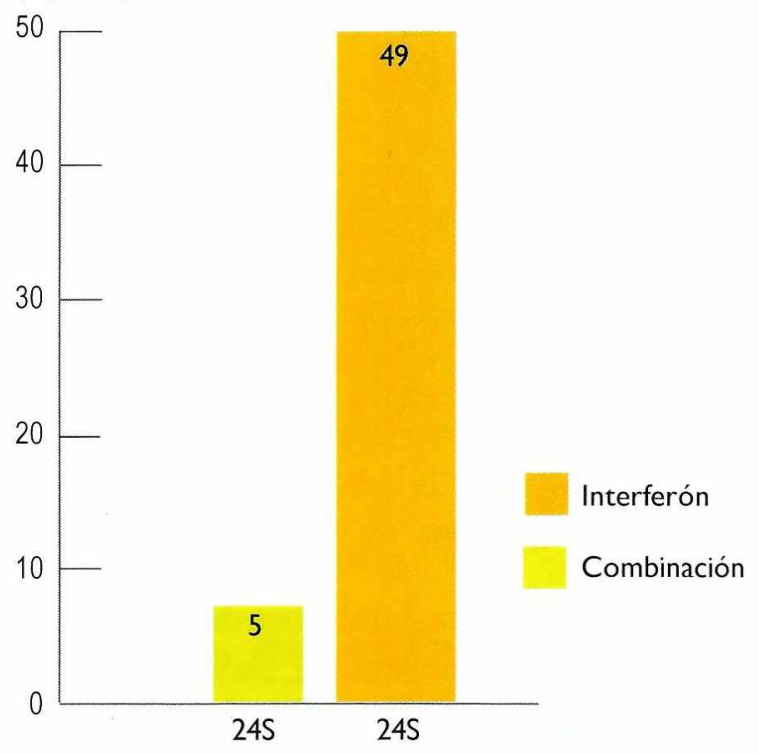

que para los pacientes con cargas altas (mayores de 2’000.000 de copias) y genotipo 1, es necesario el tratamiento combinado por lo menos durante un año, para obtener una respuesta sostenida aceptable, mientras que en los sujetos con cargas virales bajas (inferiores a 2'000.000 de copias) y genotipo diferente a 1 , por lo general son suficientes seis meses de tratamiento para alcanzar los resultados mencionados.

El interferón alfacon-1 en altas dosis (15 mcg TIW) también ha sido aprobado hace poco en los Estados Unidos para el retratamiento de las recaídas, pues un estudio no controlado mostró un porcentaje de respuesta sostenida de $28 \%$ y $58 \%$ después del tratamiento durante 24 y 48 semanas, respectivamente.

\section{Pacientes no respondedores}

Un problema significativo, que permanece sin resolver, es el de los pacientes no respondedores y aquellos con recaídas. Información obtenida recientemente por Brass y colaboradores, sugiere que la terapia combinada con interferón-ribavirina puede ser, hasta cierto punto, efectiva y mejor que la monoterapia con interferón, observándose respuesta sostenida en cerca de $20 \%$ de los pacientes.

Los estudios iniciales de monoterapia permitieron demostrar que la desaparición del ARN-VHC a

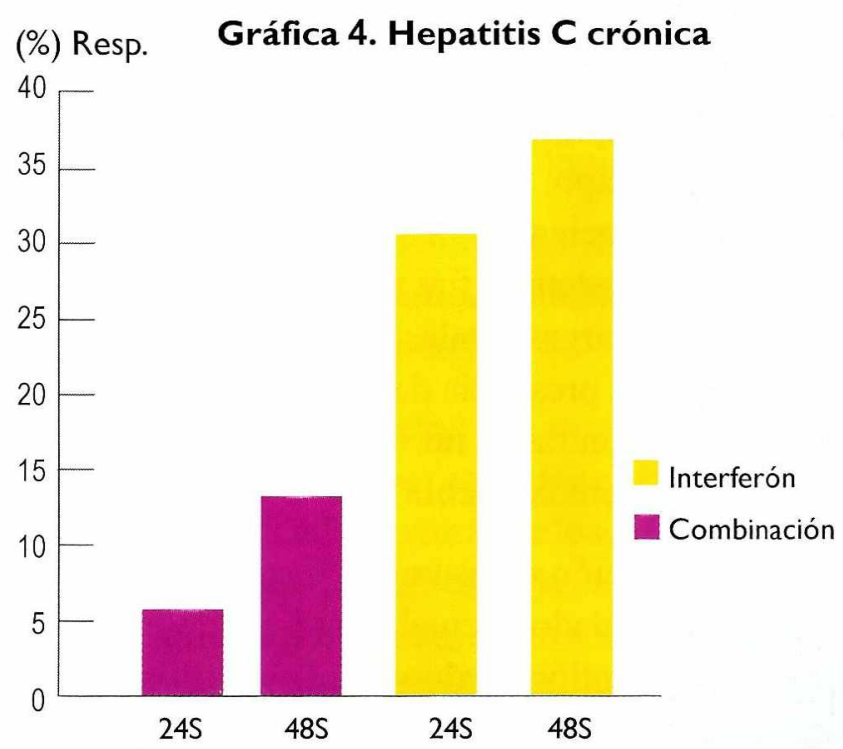


las 12 semanas después de iniciado el tratamiento era un excelente factor predictivo de respuesta sostenida $y$, en consecuencia, era poco justificable continuar el mismo tratamiento si no se cumplía esta meta. En contraste, $10-20 \%$ de pacientes en quienes no se había negativizado el ARN-VHC a las 12 semanas en los estudios combinados, lo hicieron a las 24 .

Esto indica que en el tratamiento combinado la medición de ARN-VHC debe hacerse a las 24 semanas y no a las 12 , como está indicado en el caso de la monoterapia.

La respuesta sostenida después de monoterapia y de terapia combinada ha llevado a los investigadores a referirse por primera vez a la "curación " de la hepatitis C, ya que los estudios de seguimiento a corto y mediano plazo realizados por Lam y colaboradores y Marcellini y colaboradores, han demostrado persistencia de la respuesta completa con normalización de la ALT, negativización tisular y plasmática del ARN-VHC y mejoría histológica significativa (Tablas 9 y 10).

La presencia de cirrosis compensada no es una contraindicación para el tratamiento con monoterapia, pero está claramente asociada con un menor porcentaje de respuesta al tratamiento.

\section{Factores predictivos de respuesta en terapia combinada}

La respuesta sostenida al tratamiento combinado fue mucho mejor que con la monoterapia, sin importar el genotipo, la carga viral o la histología. Sin embargo, en pacientes tratados con la combinación, la respuesta sostenida fue mucho más frecuente en aquellos con cargas virales bajas y con genotipo diferente al 1.La presencia de fibrosis o cirrosis compensada, en contraste, no influyó el porcentaje de respuesta sostenida (Tabla 11).

A continuación se resumen los esquemas terapéuticos recomendados actualmente en Colombia, de acuerdo al genotipo predominante y a la disponibilidad de medicamentos:
Tabla 9. Hepatitis C. Respuesta

sostenida a largo plazo (10 años).*

- Pacientes tratados con interferón alfa-2b entre 1984 y 1987 , por un periodo promedio de 52 semanas y seguidos por 6 a 13 años.

- De ellos, se tuvo respuesta sostenida:

- 5/5 HCV RNA negativos en seguimiento.

- 4/5 con ALT normal persistentemente.

- Biopsia hepática con mejoría

y ARN-VHC negativo.

*Lau DT et al : Hepatology 1998;28: I I2I-I I27

\section{Tabla 10. Hepatitis C. Respuesta sostenida a largo plazo.*}

- 80 pacientes con respuesta sostenida al INF fueron seguidos por I a 7,6 años (promedio 4,0 años):

- 93\% tenían ALT normal persistente.

- $96 \%$ HCV RNA negativo en seguimiento.

- $94 \%$ con mejoría histológica

(64\% normales o casi normales).

- 27/27 ARN-HCV negativos en el hígado.

* Maecellini $P$ et al.Ann Int Med 1997; I27:875-88I.

Tabla II. Respuesta sostenida al tratamiento, en función del genotipo, la carga viral y la histología.

\begin{tabular}{l}
$\begin{array}{l}\text { Factores } \\
\text { pretratamiento }\end{array}$ \\
\hline
\end{tabular}

\begin{tabular}{lll}
\hline Genotipo I & & \\
\hline Sí & $3,2 \%$ & $29 \%+$ \\
No & $6,5 \%$ & $74 \%$ \\
\hline
\end{tabular}

ARN-VHC $>2$

millónes de copias $/ \mathrm{mL}$

\begin{tabular}{lcl}
\hline Si & $1,5 \%++$ & $42 \%++$ \\
No & $15 \%$ & $67 \%$ \\
\hline
\end{tabular}

\begin{tabular}{lll}
\hline Fibrosis o cirrosis & & \\
\hline Sí & $2,9 \%$ & $46 \%$ \\
No & $4,5 \%$ & $49 \%$
\end{tabular}

\section{- Pacientes nuevos:}

- Interferón alfa-2b: 3 millones de unidades subcutáneas 3 veces por semana, asociado a ribavirina (1.000-1.200 mg por vía oral, repartido en 2 dosis), por un período de 6-12 meses, según el 
genotipo. Medición de ARN-VHC a las 24 semanas para continuar o no el tratamiento.

- Pacientes en recaída de monoterapia: el mismo régimen.

\section{- Pacientes no respondedores a monoterapia:} el mismo régimen.

\section{- Pacientes con hepatitis $\mathrm{C}$ aguda:}

- Interferón alfa-2b: 3 millones de unidades subcutáneas, 3 veces por semana por 6 meses.

En casos de infección con genotipos no 1 y baja carga viral, estaría justificado el tratamiento con monoterapia de interferón alfa- $2 \mathrm{~b}$ a dosis de $6 \mathrm{mi}-$ llones de unidades subcutáneas 3 veces por semana por 12 meses, si no está disponible la ribavirina.

\section{Nuevas alternativas terapéuticas}

Con el propósito de mejorar aun más los porcentajes de respuesta sostenida al tratamiento estudios recientes utilizando dosis mayores inicialmente por períodos variables de 3-6 meses (Inducción), parecen ser muy prometedores. Así mismo, la terapia supresora a largo plazo de acuerdo a la carga viral y el interferón de larga acción (PEGylated) son otras formas de obtener mejores respuestas. Es recomendable vacunar a todos los pacientes con hepatitis $\mathrm{C}$ crónica contra los virus de la hepatitis A y B, ya que pueden ocasionar descompensación grave de la enfermedad hepática.

En el futuro, la asociación con otros antivirales y la utilización de medicamentos con efectos específicos sobres las enzimas virales helicasa, proteasa y polimerasa, permitirá obtener mejores porcentajes de respuesta y la posibilidad de tratar a muchos de los pacientes que, en la actualidad, continúan infectados a pesar de múltiples ensayos terapéuticos.

\section{Situaciones especiales}

A pesar de los grandes avances mencionados, existe un grupo especial de pacientes para quienes toda- vía los esquemas terapéuticos son de poca utilidad, gran controversia o están contraindicados, como son:

- Los pacientes con ALT persistentemente normal por períodos de 6-12 meses.

- Los individuos con cirrosis descompensada, de diversa severidad,

- Los niños con hepatitis crónica C.

- Los pacientes con complicaciones extra hepáticas tales como crioglobulinemia, glomerulonefritis, etc.

- Los pacientes con co-infecciones por VHB y/o VIH.

- Los pacientes que han recibido transplantes.

- Las embarazadas infectadas.

- Los contactos sexuales o punciones accidentales con pacientes infectados.

\section{Efectos adversos y contraîndicaciones}

El interferón y la ribavirina no están exentos de efectos colaterales y estos deben ser bien conocidos por el médico tratante y el paciente.

Interferón: fiebre, malestar general, cefalea, alopecia, gingivitis, sequedad de piel, mialgias, artralgias, pérdida de peso, depresión, hemorragias retinianas, neumonitis, neuritis, depresión medular, hiperglicemia, hipertrigliceridemia, tiroiditis y exacerbación de enfermedades autoinmunes.

Ribavirina: anemia hemolítica, hiperuricemia, decaimiento general, insuficiencia cardíaca y confusión en pacientes cirróticos.

La mayoría de los efectos son reversibles con la disminución de la dosis por períodos cortos de tiempo. Sin embargo, en la mayoría de los estudios entre $92 \%$ y $96 \%$ de los pacientes en recaída completaron el tratamiento y el seguimiento y de $68 \%$ a $88 \%$ de los pacientes nuevos también lo hicieron. En el primer grupo se presentaron eventos adversos se- 
genotipo. Medición de ARN-VHC a las 24 semanas para continuar o no el tratamiento.

\section{- Pacientes en recaída de monoterapia: el} mismo régimen.

\section{- Pacientes no respondedores a monoterapia:} el mismo régimen.

\section{- Pacientes con hepatitis $\mathbf{C}$ aguda:}

- Interferón alfa-2b: 3 millones de unidades subcutáneas, 3 veces por semana por 6 meses.

En casos de infección con genotipos no 1 y baja carga viral, estaría justificado el tratamiento con monoterapia de interferón alfa- $2 \mathrm{~b}$ a dosis de $6 \mathrm{mi}-$ llones de unidades subcutáneas 3 veces por semana por 12 meses, si no está disponible la ribavirina.

\section{Nuevas alternativas terapéuticas}

Con el propósito de mejorar aun más los porcentajes de respuesta sostenida al tratamiento estudios recientes utilizando dosis mayores inicialmente por períodos variables de 3-6 meses (Inducción), parecen ser muy prometedores. Así mismo, la terapia supresora a largo plazo de acuerdo a la carga viral y el interferón de larga acción (PEGylated) son otras formas de obtener mejores respuestas. Es recomendable vacunar a todos los pacientes con hepatitis $\mathrm{C}$ crónica contra los virus de la hepatitis A y B, ya que pueden ocasionar descompensación grave de la enfermedad hepática.

En el futuro, la asociación con otros antivirales y la utilización de medicamentos con efectos específicos sobres las enzimas virales helicasa, proteasa y polimerasa, permitirá obtener mejores porcentajes de respuesta y la posibilidad de tratar a muchos de los pacientes que, en la actualidad, continúan infectados a pesar de múltiples ensayos terapéuticos.

\section{Situaciones especiales}

A pesar de los grandes avances mencionados, existe un grupo especial de pacientes para quienes toda- vía los esquemas terapéuticos son de poca utilidad, gran controversia o están contraindicados, como son:

- Los pacientes con ALT persistentemente normal por períodos de 6-12 meses.

- Los individuos con cirrosis descompensada, de diversa severidad,

- Los niños con hepatitis crónica C.

- Los pacientes con complicaciones extra hepáticas tales como crioglobulinemia, glomerulonefritis, etc.

- Los pacientes con co-infecciones por VHB y/o VIH.

- Los pacientes que han recibido transplantes.

- Las embarazadas infectadas.

- Los contactos sexuales o punciones accidentales con pacientes infectados.

\section{Efectos adversos y contraindicacilones}

El interferón y la ribavirina no están exentos de efectos colaterales y estos deben ser bien conocidos por el médico tratante y el paciente.

Interferón: fiebre, malestar general, cefalea, alopecia, gingivitis, sequedad de piel, mialgias, artralgias, pérdida de peso, depresión, hemorragias retinianas, neumonitis, neuritis, depresión medular, hiperglicemia, hipertrigliceridemia, tiroiditis y exacerbación de enfermedades autoinmunes.

Ribavirina: anemia hemolítica, hiperuricemia, decaimiento general, insuficiencia cardíaca y confusión en pacientes cirróticos.

La mayoría de los efectos son reversibles con la disminución de la dosis por períodos cortos de tiempo. Sin embargo, en la mayoría de los estudios entre $92 \%$ y $96 \%$ de los pacientes en recaída completaron el tratamiento y el seguimiento y de $68 \%$ a $88 \%$ de los pacientes nuevos también lo hicieron. En el primer grupo se presentaron eventos adversos se- 
rios en $10 \%$ y en el segundo en $17 \%$. Los eventos adversos más importantes fueron: cardiovasculares $(0,9 \%)$, psiquiátricos $(1,1 \%)$, gastrointestinales $(0,6 \%)$, respiratorios $0,4 \%)$ y cutáneos $(0,1 \%)$.

Los interferones están contraindicados, o deben utilizarse con suma precaución, en pacientes con citopenias significativas, depresión o trastornos psiquiátricos, falla cardiaca, diabetes no controlada, convulsiones o enfermedades autoinmunes tales como la psoriasis, la artritis reumatoide, el lupus eritematoso sistémico y la enfermedad inflamatoria intestinal.

Por su parte, la ribavirina está contraindicada en casos de anemia, falla cardiaca descompensada e insuficiencia renal crónica. Como es claramente teratogénica no debe utilizarse en el embarazo y debe evitarse el embarazo durante seis meses después de terminar el tratamiento.

\section{Conclusiones}

Aunque la monoterapia con los interferones ha representado un gran avance en el tratamiento de la hepatitis $\mathrm{C}$, la terapia combinada asociada a la ribavirina es más efectiva para la obtención de respuesta sostenida con desaparición definitiva del ARN-VHC. La adición de ribavirina no representa un aumento significativo de los efectos adversos comparados con la monoterapia con interferón, aunque algunos efectos adversos leves como el prurito, la disnea, el brote cutáneo y la anorexia, se observan más frecuentemente con la combinación.

La anemia hemolítica y la hiperuricemia son consecuencia directa de la ribavirina y pueden controlarse fácilmente con la disminución temporal de las dosis; en los casos de suspensión definitiva del tratamiento, la causa más frecuentemente fue la depresión.

Los estudios de costo/beneficio han demostrado claramente el beneficio obtenido en términos de calidad de vida, años de vida ganados y ahorro en términos de menor inversión en salud en los pacientes tratados, comparados con los no tratados.
Por primera vez en muchos años; se está hablando de "curación", con base en los estudios de seguimiento por más de 10 años realizados en pacientes con respuesta sostenida a la monoterapia o a la terapia combinada. En el futuro cercano será posible mejorar en forma sustancial la respuesta sostenida utilizando dosis mayores, más frecuentes y que incluyan la inducción por periodos variables de tiempo. La introducción de nuevos antivirales en combinación con los tratamientos actuales será, sin duda, la medida más importante en la terapia de la hepatitis $\mathrm{C}$ en las próximas décadas.

\section{Lecturas recomendadas}

1. National Institutes of Health. National Institutes of Health Consensus Development Conference Panel statement: management of hepatitis C. Hepatology. 1997; 26(suppl 1): 2S-10S.

2. Poynard T, Leroy V. Cohard M et al. Meta-analysis of interferon-randomized trials in the treatment of viral hepatitis $C$ : effects of dose and duration. Hepatology. 1996; 24: 778-789.

3. Schalm SW, Hansen BE, Chemello Let al. Ribavirin enhances the efficacy but no the effects of interferon in chronic hepatitis C. Meta-analysis of individual patient data from European centers. J Hepatology. 1997; 26: 961-966.

4. Lai MY, Kao JH, Yang PM, et al. Long-term efficacy of ribavirin plus interferon in the treatment of chronic hepatitis $\mathrm{C}$. Gastroenterology. 1996; 111: 1307-1312.

5. Davis GL, Lau JY, et al. Factors predictive of a beneficial response to therapy of hepatitis C. Hepatology. 1997; 26: 122s-127s.

6. Reichard O, Foberg U, Fryden A, et al. High sustained response rate and clearance of viremia in chronic hepatitis $\mathrm{C}$ after treatment with interferon a-2b for 60 weeks. Hepatology. 1994; 19: 280-285.

7. Davis GL, Esteban-Mur R, Rustgi V et al. Interferon apha$2 \mathrm{~b}$ alone or in combination with ribavirin for the treatment of relapse of chronic hepatitis C. New Engl J Med. 1998; 339: 1493-1499.

8. Lampertico P, Rumi M, Romeo R et al. A Multicenter Randomized Controlled Trial of Recombinant alfa- $2 b$ in Patients with Acute Transfusion-associated Hepatitis C. Hepatology. 1994; 19: 19-22.

9. McHutchison JG, Poynard T et al. Combination Therapy With Interferon Plus Ribavirin for the Initial Treatment of Chronic Hepatitis C. Seminars in Liver Disease. 1999; 19, Suppl. 1: 57-65.

10. Poynard T, Marcellini P, Lee S, et al. Randomised trial of interferon alpha- $2 \mathrm{~b}$ and ribavirin for 48 weeks or for 24 weeks versus interferon alpha- $2 \mathrm{~b}$ plus placebo for 48 weeks for the treatment of chronic infection with hepatitis $\mathrm{C}$ virus. Lancet. 1998; 352: 1426-1432.D 
11. Di Biscegli AM. Treatment advances in chronic hepatitis C. Seminars in Liver Disease. 1999;19(1):1-112.

12. Foster GR, Goldin RD and Thomas HC. Chronic Hepatitis C Virus Infection Causes a Significant Reduction in Quality of Life in the absence of Cirrhosis. Hepatology. 1998; 27: 209-12.

13. Bennet WG, Inoue Y, Beck R et al. Estimates of the CostEffectiveness of a Single Course of Interferon-Alfa 2-b in Patients with Histological Mild Chronic Hepatitis C. Ann Intern Med. 1997; 127: 855-865.

14. Lau DTY, Kleiner DE, Ghany MG et al. 10 Year follow-up
After Interferon-alpha Therapy for Chronic Hepatitis C. Hepatology. 1998; 28: 1121-1127.

15. Marcellin P, Boyer N, Gervais A et al. Long-Term Histologic Improvement and Loss of Detectable Intrahepatic HCV RNA in Patients with Chronic Hepatitis C and Sustained Response to Interferon-alpha Therapy. Ann Intern Med. 1997; 127 (10): 875-881.

16. Reichard O, Norkrans G, Fryden A et al. Randomized double-blind, placebo-controlled trial of interferon alpha- $2 \mathrm{~b}$ with and without ribavirin for chronic hepatitis C. Lancet. 1998; 351: 83-86.

\section{Prevención de la transmisión de la hepatitis C}

Mauricio Beltrán Durán. M.D.*

De acuerdo a la epidemiología de la hepatitis en los donantes de banco de sangre, estas instituciones deben servir de unidades de vigilancia de enfermedades en donantes de sangre, en la población de bajo riesgo o no sintomática; para ello, es necesario continuar y organizar la vigilancia de enfermedades transmitidas por transfusión, con el fin de capacitar y asesorar a los bancos de sangre en la selección de donantes, el análisis de información del donante (tanto de la encuesta como de los resultados serológicos) y en la evaluación de los reactivos para uso en bancos de sangre.

Los datos de vigilancia epidemiológica correspondientes a las seccionales de salud del Chocó, Boyacá, Antioquia, Atlántico mostraron, de manera consistente, una baja cobertura de tamizaje para anticuerpos anti-VHC en las unidades de sangre obtenidas.

Con el fin de promover las estrategias de prevención es necesario:

- Incrementar el tamizaje de las unidades sangre recolectadas para acercarse a una cifra de 100\% (Gráfica 5).
- Reducir el porcentaje de unidades de sangre descartadas por reactividad a anticuerpos anti-VHC, efectuando una mejor selección del donante a través de las preguntas pertinentes respecto a los factores de riesgo para hepatitis $\mathrm{C}$, como tatuajes y uso de drogas intravenosas.

- Dado que la población de donantes de sangre es generalmente asintomática y de bajo riesgo, las prevalencias halladas para anticuerpos anti-VHC, podrían utilizarse para determinar la existencia de zonas endémicas para hepatitis $\mathrm{C}$.

$\mathrm{El}$ riesgo de adquirir hepatitis $\mathrm{C}$ por vía transfusional ha disminuido, debido al aumento de la cobertura de tamizaje para este marcador y la utilización de pruebas tipo ELISA, más sensibles y especificas; sin embargo, la transfusión con "riesgo cero" no puede lograrse en la actualidad, por tanto es necesario hacer un uso racional de la sangre y sus componentes.

Los bancos de sangre, como unidades de vigilancia de enfermedades en donantes de sangre, deben remitir, a través de las Direcciones de Salud, a los servicios de atención médica a todos aquellos donantes doblemente reactivos a las pruebas de tamizaje, para que sean evaluados clínica y serológicamente y formen parte de los correspondientes sistemas de vigilancia en salud pública. 


\section{Gráfica 5. Algoritmo para la selección de unidades de sangre, tamizaje en banco de sangre, remisión del donante de riesgo.}

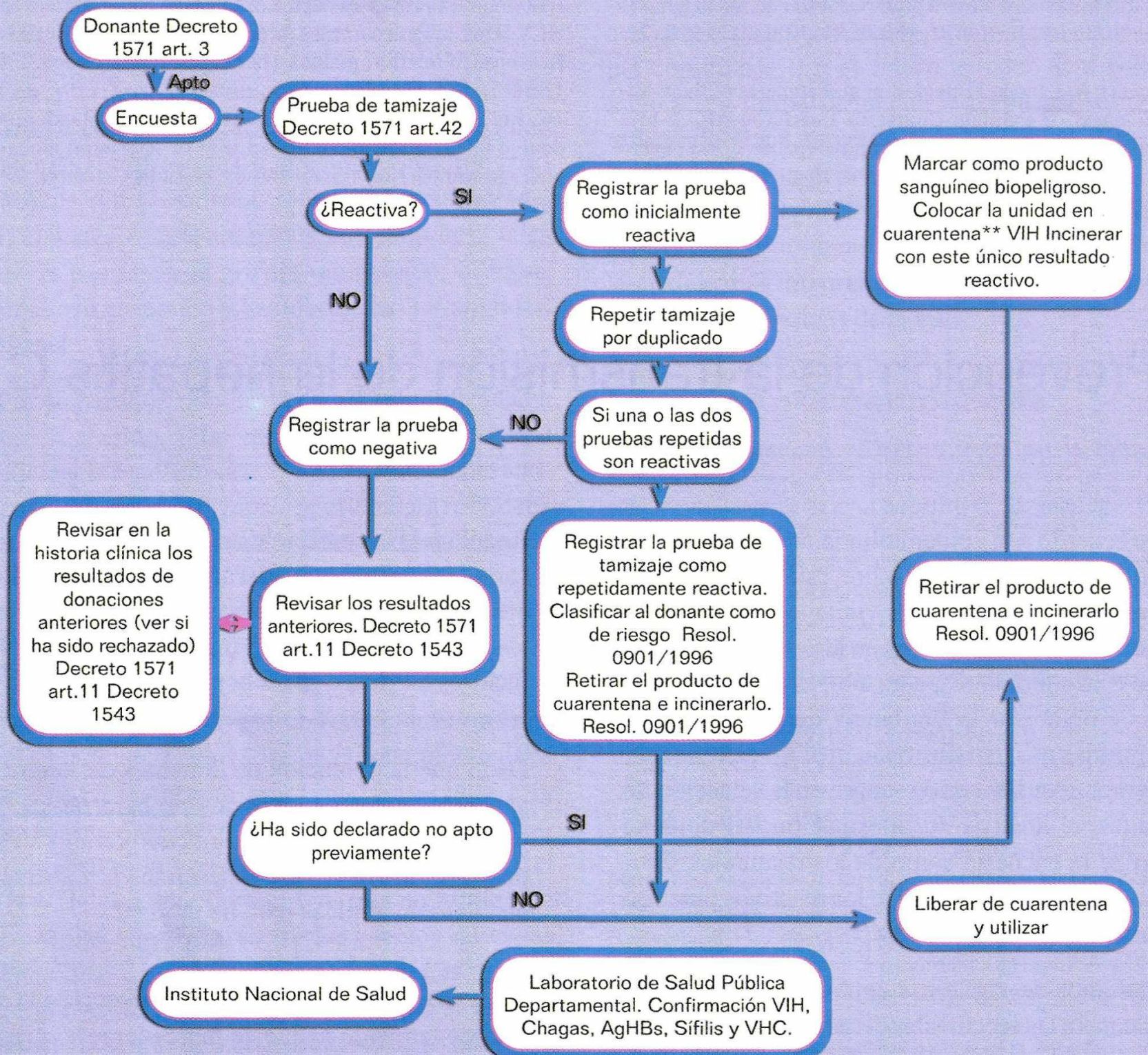

Es necesario desarrollar un sistema de vigilancia epidemiológica de las actividades realizadas por los bancos de sangre para reducir la transmisión de enfermedades por vía transfusional y mejorar la calidad de la sangre y hemoderivados. Ello permitirá:

- La selección de donantes de bajo riesgo, mediante la orientación a los bancos de sangre en la selección de donantes repetitivos.

- El suministro de información epidemiológica que apoye las decisiones del equipo terapéutico, me- jore la calidad de la hemoterapia y la administración del sistema desde el nivel nacional hasta el nivel local.

- Captar el donante de "riesgo" y remitirlo a las instituciones competentes para su atención.

\section{Pautas a seguir en donantes de riesgo}

Se considera donante "de riesgo" cuando la encuesta o los análisis de laboratorio de su sangre, 
sugieran que el individuo está o ha estado expuesto al riesgo de infección transmisible por la sangre o de una enfermedad que contraindique la donación.

En tal caso se generan las siguientes decisiones:

- Cancelación de la flebotomía, si ésta no se ha producido.

- Confirmación del riesgo del donante en un laboratorio de referencia.

- Clasificación del producto sanguíneo (si se hubiese obtenido), como producto sanguíneo de riesgo potencial e incineración del mismo..

- Notificación precisa y oportuna al sistema de vigilancia.

Para el caso de los análisis de laboratorio, donante de riesgo es todo individuo a quien los análisis de su unidad de sangre dan resultados doblemente reactivos en pruebas de tamizaje, realizadas por cualquier técnica.

\section{Lecturas recomendadas}

1. Beltrán M, Ayala M, Ching R. Enfermedades transmitidas por la sangre. Una historia un compromiso INS. 1998: 329-342.

2. Murphy EL, Bryzman William AE, et al. Demographic determinants of hepatitis $\mathrm{C}$ virus seroprevalence among blood donors. JAMA. 1996,275 (13): 995-1000.

3. Aach RD. Stevens CE. Hollinger FB. et al. Hepatitis C Virus Infection in post-transfusion Hepatitis. N Engl J Med. 1990. 325:1325-1329.

4. Botero R C, Rojas E, Idrovo V, et al. Genotipos del virus de la hepatitis C (HVC) en Santafé de Bogotá. Rev Col Gastroenterol. 1997; XII: 15-20.

5. Santamaría C, De Lima E, Holguín J. Hallazgos histológicos en infección crónica por el virus de la hepatitis C y su correlación con el genotipo viral, en Cali. Colombia médica. 1998; 29: 20-23.

6. Cortes A, Holguín J. Enfermedad hepática subclínica en donantes voluntarios de sangre con anticuerpos contra hepatitis C. Colombia Med. 1994; 25:142- 44.

7. Beltrán M, Ayala M, Ching R. Situación actual del tamizaje en bancos de sangre. Biomédica. 1997, 16 2:51-52.

8. Cortés Armando. Marcadores para enfermedades transmitidas por la sangre. Revista de Medicina Transfusional. 1994 1(1): 10-13.

9. Beltrán M, Ayala M. Impacto del tamizaje para anticuerpos antivirus de hepatitis $\mathrm{C}$ en la reducción de la transmisión de hepatitis C. Boletín Red de Sangre. Instituto Nacional de Salud. 1998, 2 (12): 1-4.

\title{
Mesa redonda y recomendaciones
}

\section{¿Cuál es el papel de los genotipos, especies y cuasiespecies?}

\author{
Dr. Rolando Ortega*
}

Es muy importante reconocer que el virus de la Hepatitis $\mathrm{C}$ es un virus muy complejo, que, al igual que todos los virus ARN se replica a través de una polimerasa de ARN imperfecta, de tal forma que durante el proceso de replicación esta enzima es incapaz de corregir los errores que ocurren durante el mismo. Desde cuando se identificó la biología molecular de este virus en el año de 1989 por el doctor Huig, comenzó a notarse existían varios tipos de

* Internista y gastroenterólogo. Servicio de Gastroenterología y Hepatología, Clínica Enrique de la Vega, I.S.S. Cartagena. virus, diferenciables entre sí por su secuencia de nucleótidos. En 1990 comenzó a hablarse del concepto de diferentes genotipos, los cuales son el resultado de las mutaciones del virus de hepatitis $\mathrm{C}$ (VHC) en la naturaleza.

En 1993 el doctor Peter Simmonds, de la Universidad de Edimburgo, presentó la clasificación más aceptada, la cual incluye seis genotipos cuya diferenciación se establece teniendo en cuenta que la homología en la secuencia de nucleótidos es menor de $65 \%$; cuando la homología es de $75 \%-85 \%$ se habla de los diferentes subtipos. 
de 1993, por eso se están identificando en este momento, con la disponibilidad de pruebas de tamización, las personas que han entrado en contacto con el virus; esto es muy importante al hablar de epidemia en el futuro y hay que considerar que en Colombia $99,9 \%$ de las unidades de sangre han sido tamizadas y se eliminan cuando son serorreactivas. Es decir que en el país ocurrirá una epidemia de enfermedad crónica como efecto de la cohorte de los pacientes infectados en el pasado.

La principal causa de infección de los pacientes en Colombia es la transfusión de sangre contaminada. Los datos también permiten concluir, que la importancia de la vigilancia de las ictericias, pero sobre todo de las hepatitis, podría ser una recomendación para el Ministerio de Salud.

En este momento, el Ministerio de Salud de Colombia esta interesado sólo en la vigilancia de la hepatitis $\mathrm{B}$, porque es una enfermedad para la cual ya se iniciaron medidas preventivas, desde 1995, consistentes en la vacunación de los menores de un año en zonas de baja endemicidad y los menores de cinco años en las zonas de alta endemicidad; sin embargo, es importante resaltar la importancia de clarificar la etiología de las diferentes hepatitis y hacer una vigilancia como lo hace la secretaría de salud de Bogotá para todos los síndromes de ictericia aguda, hasta aclarar la etiología viral de alguno de ellos.

La importancia de la investigación en los casos captados por donación, en este momento, es impor- tante para predecir la evolución de la historia natural de la enfermedad en nuestro medio, adicionalmente es importante el trabajo interdisciplinario y la colaboración entre los clínicos, los salubristas públicos y los epidemiólogos para establecer las medidas de prevención más adecuadas de acuerdo con los riesgos poblacionales.

Dr. Enrique Ponce de León: en 1994 el tamizaje no llegaba sino a 22\%; ¿Cuándo se llegó realmente a $99 \%$ ?

Dr. Mauricio Beltrán: en 1993, exactamente, el tamizaje era del 22\% de las unidades, en 1994 fue superior a $97 \%$ y en 1998 es de $99,9 \%$ y sólo quedan por tamizar, en algunas seccionales, unos pocos bancos de sangre. Además, la determinación de genotipo es muy importante para decidir el tipo de tratamiento, la duración del mismo y la respuesta esperada.

\section{Comentario}

Dr. Roberto León: es muy importante buscar nuevos factores de riesgo, adicionales a la transmisión sexual y la transmisión transfusional, como son otras vías parenterales entre ellas los tatuajes, el piercing, la mesoterapia o la acupuntura con agujas no esterilizadas y no se si habrá estudios que estén dirigidos a esto, pero definitivamente parte de la prevención que se tocará mas adelante, debe también concientizar a la población en este tipo de cosas.

\section{¿Cuál es la historia natural de la hepatitis $\mathrm{C}$ en Colombia?}

Dr. Julián Martínez**

La historia natural de la hepatitis C en Colombia no difiere de los demás estudios e informes de otras

\footnotetext{
Coordinador Unidad de Gastroenterología, Hospital Universitario de la Samaritana, Bogotá.
}

latitudes del mundo; la mayoría de los pacientes que sufre una infección aguda, o infección primaria, no presenta síntomas clínicos; se calcula que $70 \%$ de los pacientes con infección primaria cursan asinto- 
máticos y un $30 \%$ hace el cuadro de hepatitis aguda caracterizado por ictericia, malestar general y elevación de las aminotransferasas.

El periodo de incubación para la infección por el virus de la hepatitis $\mathrm{C}$ es, en promedio, de siete semanas, con un rango que puede ir de tres a veinte semanas.

Solo $15 \%$ - $25 \%$ de los pacientes que hacen infección primaria de hepatitis aguda depuran el virus y el resto se vuelven portadores crónicos de la enfermedad, de los cuales, según el tiempo y ciertas características, alrededor de $20 \%$ van a desarrollar formas graves de enfermedad hepática como la cirrosis; según estudios europeos, cada año 3\% a 5\% de los enfermos con cirrosis desarrollan hepatocarcinoma.

El desarrollo de hepatitis crónica tiene un promedio de 10 años y el de la hepatitis crónica con mayor severidad, cuya principal manifestación clínica es un cuadro de astenia, adinamia, fatigabilidad y elevación de las aminotransferasas, se calcula que pueda durar hasta 18 años, la presencia de cirrosis, 22 años y el de hepatocarcinoma hasta 30 años.

Algunos pacientes, a pesar de persistir con la infección, no desarrollan ningún cuadro clínico y son los que se encuentran en las pruebas de tamizaje o como donantes de sangre; estas personas, por lo general, fallecen por causas diferentes a la enfermedad hepática.

Entre los factores que alteran el curso de la enfermedad, el genotipo viral es uno de los más importantes, ya que el genotipo 1 del VHC es más agresivo y de peor pronóstico, pues responde menos a las estrategias terapéuticas. Precisamente, este genotipo es el más frecuente en Colombia. Otros factores de importancia incluyen las cargas virales altas, como son las que tienen lugar cuando la infección se adquiere por transfusiones, y la presencia de cuasiespecies, que pueden contribuir a un curso de peor pronóstico.

En cuanto a las características del hospedero o del paciente, el pronóstico es peor en los hombres, en los sujetos mayores de 40 años y en los individuos de otras razas diferentes a la blanca. Por último, otros factores que ensombrecen el pronóstico son el consumo de alcohol y la coinfección por otros virus (como el virus de la hepatitis A o el virus de la hepatitis B), porque están asociados al desarrollo de formas fulminantes de la enfermedad.

En las infecciones primarias, un porcentaje mínimo de pacientes desarrolla un cuadro sintomatológico similar a la influenza, otros enfermos presentan ictericia y malestar general, en tanto que la mayoría de primoinfectados no experimentan síntomas iniciales; pero al pasar el tiempo pueden desarrollar cuadros clínicos compatibles con insuficiencia hepática crónica, cirrosis, hepatocarcinoma y sus complicaciones.

\section{Comentario}

Dr. Rafael Claudino Botero: aunque la coinfección del VHC con otros virus de hepatitis es más agresiva, es preciso señalar que en Colombia se ha observado cómo la mayoría de los niños con cáncer, sometidos a quimioterapia y con infección por virus $\mathrm{B}$ y $\mathrm{C}$ de la hepatitis, desarrollan formas más leves de la enfermedad, que aquellos infectados únicamente por un tipo de virus (B o C). La causa de este fenómeno es desconocida y hasta ahora comienza a estudiarse.

Dra. Patricia Álvarez: ¿Está justificado el tratamiento de los pacientes con cirrosis compensada o fibrosis leve?.

Dr. Rafael Claudino Botero: definitivamente la presencia de inflamación y fibrosis, predice la progresión a cirrosis y en estos pacientes el tratamiento muestra una mayor relación costo/beneficio, porque el tratamiento puede evitar las graves consecuencias a largo plazo de la infección. En contraste, entre los pacientes sin fibrosis y mínima inflamación el riesgo de progresión a enfermedad hepática grave, a 10 años, es inferior a $7 \%$.

Dr. Mario Santacoloma: ¿En el paciente que por un hallazgo incidental se le encuentra un anticuerpo 
para la hepatitis $\mathrm{C}$ positivo y en los controles mensuales hay valores alternantes entre normales y ligeramente elevados de transaminasas y de aminotransferasas, se justifica hacer una biopsia?

Dr. Víctor Idrovo: hay que considerar la presencia de factores de riesgo. En los pacientes que tienen factores de riesgo y transaminasas elevadas, o con una prueba de ELISA positiva hay una alta probabilidad de hepatitis C, pues la sensibilidad y especificidad de la prueba de ELISA son superiores a 95\%; en estos casos, para decidir si se va a comenzar el tratamiento, es necesario determinar la carga viral y realizar una biopsia hepática porque son pronosticadores importantes de la respuesta terapéutica. Por otro lado, en los pacientes sin factores de riesgo y transaminasas normales, hay que llevar a cabo una prueba confirmatoria y si esta es negativa, no se justifican otros estudios adicionales, ya que puede decirse que no tienen la enfermedad, por lo que es innecesario practicar una carga viral o una biopsia hepática.

Dr. Roberto León: ¿Qué debe decirle el clínico a un paciente que llega al consultorio y tiene hepatitis $\mathrm{C}$, qué debe recomendarle en cuanto a alcohol, vacunas o seguimiento?

Dr. Víctor Idrovo: cuando el paciente tiene un diagnóstico confirmado de hepatitis $\mathrm{C}$ lo primero que debe decidirse es si requiere tratamiento. Hay que hacer una evaluación muy cuidadosa y si tiene aminotransferasas persistentemente normales, aunque presente carga viral y tenga positividad por un método serológico para hepatitis $\mathrm{C}$, la conducta indicada es el seguimiento sin tratamiento, porque la probabilidad de complicaciones es muy baja y todo ello debe explicarse con claridad al paciente. De igual modo, en un sujeto con positividad confirmada para VHC, carga viral alta y elevación de transaminasas, es necesario el tratamiento, para lo cual hay que completar la evaluación, mediante una biopsia hepática. En cuanto a medidas preventivas lo más importante es vacunar a estos pacientes contra hepatitis B; con relación a la vacuna contra hepatitis $\mathrm{A}$, pienso que es más costo/efectivo solicitar anticuerpos contra VHA, para evaluar la necesidad de la vacuna. Sobre el alcoholismo, es indispensable que estos pacientes se abstengan de tomar alcohol no sólo porque el alcohol es hepatotóxico, sino porque la progresión de la enfermedad por el virus $\mathrm{C}$ se acelera cuando hay ingesta concomitante de alcohol.

\section{Comentario}

Dr. Rafael Claudino Botero: es muy importante no aterrorizar a los pacientes; hay que individualizar todos los casos y recordar que esta es una enfermedad capaz de provocar cirrosis después de 20 años o más de evolución, así como hay sujetos que no experimentan ningún tipo de complicación hepática y fallecen por otras causas. En consecuencia, la educación y la correcta información son elementos fundamentales para no provocar el pánico y atemorizar, innecesariamente, a las personas infectadas por el virus de la hepatitis $\mathrm{C}$.

\section{¿Cuáles son las pruebas diagnósticas que se deben realizar en Colombia?}

Dr. Oscar Beltrán*

Depende de tres condiciones: el contexto clínico del paciente, los costos y la disponibilidad de recursos. Respecto al primer punto, aquellos

* Internista y Gastroenterólogo, Coordinador Unidad de Gastroenterología, Clínica San Pedro Claver, Bogotá. pacientes con un anti-C positivo y aminotransferasas anormales, hay que realizar un PCR cuantitativo para establecer la carga viral, con miras a la selección del tratamiento y su duración (6 ó 12 meses). 
Otro caso es el del paciente con un anti-C positivo detectado por tamizaje, que tiene aminotransferasas normales y sin factores de riesgo.

En esta situación, la posibilidad de que el anti-C sea un falso positivo es de $50 \% \mathrm{y}$, por cuestión de costos, resulta más apropiado solicitar un PCR cualitativo que un PCR cuantitativo, pues el primero de estos exámenes es más barato y resulta suficiente para confirmar o descartar la infección.

Dr. Ponce de León: ¿Cuáles son las recomendaciones para el manejo inicial del personal de salud que ha entrado en contacto accidental con sangre de pacientes positivos para el VHC?

Dr. Víctor Idrovo: Como en todo accidente de este tipo, se deben hacer pruebas no sólo para hepatitis $\mathrm{C}$, sino para $\mathrm{VIH}$, para hepatitis B y serología. La prueba más rápida para saber si ha ocurrido la infección por VHC es la viremia por PCR, que debe hacerse a las dos semanas y probablemente puede hacerse hacia las 12 semanas una determinación de anticuerpos para complementar el seguimiento; si es negativo en ese periodo y el PCR fue negativo la infección se puede descartar.

Dr. Mauricio Rodríguez Godoy: ¿Cuál es el seguimiento después del accidente ocupacional y cuáles son los criterios de profilaxis postexposición?

Dr. Víctor Idrovo: Al momento del accidente hay que hacer una evaluación del estado serológico basal del personal de salud y se debe hacer un PCR a las dos semanas del accidente para determinar si hubo contaminación con VHC.

En el personal de salud que tiene un contacto frecuente con productos sanguíneos y una mayor probabilidad de accidentes ocupacionales, es conveniente realizar una determinación de anticuerpos anti-C cada seis meses.

Desde el punto de vista de prevención o profilaxis en el momento del contacto, no existe ningún tipo de globulinas ni gammaglobulinas útiles para prevenir la infección por VHC y tampoco hay una vacuna disponible.

\section{Comentario}

Dr. Oscar Beltrán: Hay un examen muy senci1lo, que es factor determinante en la conducta con los pacientes, aún en un accidente de trabajo, y son las aminotransferasas, porque son una opción apropiada cuando no está disponible el PCR. Como la hepatitis aguda tiene una alta posibilidad de respuesta al interferón, si detectamos un paciente con aminotransferasas elevadas estamos a tiempo de tomar una decisión y evitar que la infección se vuelva crónica en $85 \%$ de los pacientes. Vale la pena mencionar que existe mucha más preocupación por el VIH que por el VHC, cuando el riesgo de infección en accidentes de trabajo, es de apenas $0,3 \%$ por el primero de estos agentes y de $3 \%$ a $10 \%$ por el segundo; es más, el riesgo con VHB es de hasta $60 \%$ si es positivo para el antígeno e.

Dr. Carlos Gómez: ¿Qué porcentaje real de falsos positivos hay en los bancos de sangre?.

Dr. Mauricio Beltrán: Nosotros, desde el Instituto Nacional de Salud hace dos años desarrollamos un programa de propiciencia, que incluye una prueba de control de calidad, basada en paneles con resultados verdaderamente reactivos y positivos y no hemos encontrado falsos positivos, hasta la fecha, para 46 bancos de sangre que participan y recolec$\tan 70 \%$ de la sangre.

Dr. Juan Calderón: En cuanto al seguimiento de la hepatitis $\mathrm{C}$ en los bancos de sangre, en la actualidad se esta haciendo un control de calidad externo en la parte de inmunohematología e inmunoserología; la inmunoserología incluye sueros positivos para hepatitis $\mathrm{C}$, a diferentes niveles de concentración para hacer el seguimiento a los bancos de sangre, por lo menos en Bogotá. En algunos de los bancos de sangre grandes del país se está haciendo este control de calidad externo en cooperación con el Instituto Nacional de Salud y los resultados han sido muy satisfactorios.

Dr. Roberto León: desde el punto de vista clínico, e independientemente de la prevalencia de cada país, si un PCR sale negativo en un paciente con ELISA positivo no significa que este último sea un 
falso positivo, porque hasta $15 \%$ de los pacientes que adquieren la infección pueden erradicarla, es decir que la prueba de ELISA positiva indica, en estos caos, una infección pasada y no un proceso activo.
La manera de saber si la ELISA positiva es verdadera o un falso positivo es practicar un estudio con PCR y RIBA.

\section{¿Cuál es el tratamiento para los pacientes con hepatitis C, en la actualidad?}

Dr. Jaime Holguín*

De acuerdo con las evidencias actuales, es preciso tratar a aquellos pacientes con infección por $\mathrm{VHC}$, comprobada mediante una prueba de biología molecular, así como aquellos que tengan una enfermedad hepática crónica activa demostrada por una biopsia de hígado, en donde puede o no existir cirrosis, y los pacientes cirróticos compensados. Al ingresar al protocolo de tratamiento, los pacientes también deben tener unas transaminasas elevadas y debe hacerse una carga viral y un serotipo.

En segundo lugar, los pacientes con infección aguda deben tratarse debido a que en estos sujetos tienen una alta tendencia a desarrollar enfermedad hepática crónica. Hay grupos especiales de mucha controversia que incluyen los sujetos con enfermedades renales crónicas, cáncer, coinfección por VIH y los niños.

Los pacientes con biopsia hepática normal y con aminotransferasas normales no deben tratarse, según los diferentes estudios que aparecen en la literatura y de la revisión que expuso el Dr. Claudino Botero. Además, tratar pacientes con biopsia hepática normal y aminotransferasas normales, no está indicado, teniendo en cuenta el curso benigno de la enfermedad en la mayoría de estos casos; así mismo, el tratamiento es muy costoso y podría inducir la aparición de mutaciones.

Hoy en día, no hay lugar para la monoterapia en los pacientes que no han recibido tratamiento o en

* Internista y Hepatólogo, Hospital Universitario del Valle Centro Médico Imbanaco-Cali. quienes experimentan una recaída, porque han sido resistentes al tratamiento. Los pacientes nuevos deben tratarse según los criterios mencionados, mientras que los sujetos que han recaído después de un esquema de monoterapia o que no han respondido a esta modalidad terapéutica ameritan terapia con interferón alfa dos $\mathrm{B}$, a una dosis de 3 millones de unidades tres veces por semana, administrada por vía subcutánea, más ribavirina a una dosis que oscila entre 1.000 a $1.200 \mathrm{mg} /$ día, repartida en dos tomas, durante un periodo de 11 meses, dependiendo por supuesto del genotipo viral. Hay que medir el RNA a los tres meses porque esto permite decidir si es necesario continuar el tratamiento.

\section{Comentario}

Dr. Rafael Claudino Botero: Aunque se recomienda tomar la carga viral a los tres meses de tratamiento, los últimos estudios de McHutchison y Davis reportaron que $20 \%$ de los pacientes al cabo de tres meses no habían respondido al tratamiento combinado, pero sí lo hicieron a los seis meses de terapia continua. Por eso, en los enfermos tratados con interferón y ribavirina, es preferible realizar la carga viral cualitativa a los seis meses y no a los tres meses.

Dr. Herman Rodríguez. El grupo japonés, mostró que el interferón funciona muchísimo mejor cuando se da en dosis de cinco millones de unidades, no de tres; entonces, ¿no sería una pérdida tanto de dinero del paciente como de actividad biológica del interferón emplear la dosis de tres millones de unidades? 
Dr. Jaime Holguín: Además de la experiencia japonesa, varios grupos americanos han propuesto una terapia que se llama terapia de inducción, en la cual están utilizando dosis mayores de las de tres millones y se sabe que una terapia de este tipo, que oscila entre dos y tres meses, con administración diaria de interferón podría dar una respuesta mucho más temprana.

Además, dicha estrategia permite evaluar a los pacientes de una manera muy precoz y distinguir entre quienes responden y quienes no lo hacen, para no esperar seis meses; sin embargo, se trata de unos pocos estudios y como estamos en el contexto de un consenso, hay que reunir la experiencia que hoy es aceptada en los grupos grandes de investigación, donde se han hecho estudios controlados a gran escala.

Dr. Rafael Claudino Botero: el punto es que la terapia de inducción y el uso de dosis más altas, no presentan una diferencia muy significativa en cuanto a la respuesta sostenida a largo plazo, con respecto al tratamiento con dosis menores e intermitentes.

Inicialmente, la respuesta terapéutica es muy dramática en los esquemas de dosis altas, pero a medida que pasa el tiempo no hay mayor diferencia en los resultados finales, entre dicha estrategia y el tratamiento usual intermitente y de dosis más bajas. Todavía no existe información suficiente para favorecer los esquemas de dosis altas, que son, por otra parte, mucho más costosos y no existe consenso al respecto.

Dr. Herman Rodríguez: ¿Cómo es el comportamiento de las entidades de salud, con respecto al costo del tratamiento?

Dr. Rafael Claudino Botero: el interferón está incluido en el formulario del plan obligatorio de salud, así que en teoría cualquier EPS tiene que suministrarlo y cubrir los costos del tratamiento.

El punto no es cuánto cuesta la terapia, sino cuánto se ahorra la sociedad con el tratamiento oportuno.
Hay que ver cuál es el costo social real de un individuo no tratado que está diseminando la enfermedad.

La mayoría de las EPS suministra el interferón, pero persisten algunos problemas con la ribavirina, medicamento que está en proceso de aprobación por parte del Invima.

\section{Comentario}

Dra., Gladys Espinosa: esa es la segunda parte del problema, pues la primera es la dificultad para la realización de los exámenes de confirmación diagnóstica, en los sujetos con una ELISA positiva.

El manual de procedimientos e intervenciones del plan obligatorio de salud, más conocido como MAPIPOS, tiene una serie de vacíos en el caso de la hepatitis y sólo considera las pruebas diagnósticas para la hepatitis B y delta, en tanto que no están incluidas las pruebas diagnósticas para hepatitis A o hepatitis $\mathrm{C}$.

En todo caso, el mismo MAPIPOS tiene un parágrafo que dice que cualquier prueba para diagnosticar una enfermedad debe ser cubierta por el plan obligatorio de salud y que no está excluida; sin embargo, como no es explícito en el listado las aseguradoras no siempre se la garantizan a las personas afiliadas.

Dr. Fernando Peñalosa: ¿Es igualmente desalentadora la respuesta sostenida a la monoterapia con interferón en los pacientes tratados crónicamente, es decir, después de dos o más meses de contraída la infección, que en quienes son tratados de forma aguda?.

Dr. Rafael Claudino Botero: no, la diferencia es grande; en la punción accidental, si el control resulta positivo para el ácido nucleico, estas personas pueden entrar a un régimen de tres millones de unidades tres veces por semana durante tres meses y el porcentaje de respuesta sostenida satisfactoria oscila entre $60 \%$ y $70 \%$. 


\section{¿Cuáles son las medidas preventivas actuales en Colombia para la Hepatitis C?}

Dr. Juan Carlos Calderón

Las medidas preventivas para hepatitis C consisten en seguir dos lineamientos básico principales: uno que está dirigido a la educación de la población general, acerca del manejo de la enfermedad como tal y el manejo de los contactos del paciente positivos para hepatitis $\mathrm{C} y$, por otro lado, hay que intervenir en los bancos de sangre, como los principales entes en los que se está haciendo un seguimiento a la población de bajo riesgo.

Hay todo un proceso mediante el cual la persona ingresa a donar sangre: primero se le aplica una ficha de exclusión, para establecer los factores de riesgo. Posteriormente, se toma en estos donantes una muestra para hacer una prueba de ELISA, que en la mayoría de los bancos de sangre en Bogotá, consiste en un ELISA de tercera generación para hepatitis C. No obstante, en algunos bancos de sangre del país todavía se sigue haciendo con ELISA de segunda generación.

La exposición de algunas personas a múltiples donantes o todos los que reciben múltiples transfusiones o transfusiones de plaquetas, se puede obviar usando los métodos de aféresis, que es la colecta de plaquetas o de plasma de un solo donante para hacer este tipo de procedimientos; esta es una buena alternativa para reducir el riesgo.

Por otro lado, también se está trabajando en el seguimiento de los donantes; todos los donantes reactivos en banco de sangre se están remitiendo a vigilancia epidemiológica, para el correspondiente seguimiento y se hace el contacto con la respectiva EPS, para que sea la encargada del resto de pruebas de confirmación diagnóstica.

* Director Médico, Banco de Sangre. Clínica San Diego, Unidad de Banco de Sangre, Secretaría Distrital de Salud, Bogotá.
De esta forma, los bancos de sangre no son los encargados de hacer el diagnóstico, sino que tienen la responsabilidad de realizar una encuesta de tamizaje y dirigir al paciente hacia un sistema de salud, donde se haga el diagnóstico, ya que los bancos de sangre no cuentan con la infraestructura ni el personal para hacerlo.

\section{Comentario}

Dr. Mauricio Beltrán: el papel de los bancos de sangre es tamizar y el papel de las seccionales regionales apoyadas en los laboratorios de salud pública es hacer, para cada muestra reactiva de hepatitis C, un ELISA de tercera generación. Luego, junto con los sistemas de vigilancia epidemiológica hacen la remisión del paciente a la EPS, para que esta continúe el proceso diagnóstico y de tratamiento.

Dra. Gladys Espinosa: respecto a la tamización de los transfundidos antes de 1993, Colombia no tiene las condiciones para hacer un programa de tamización poblacional para hepatitis $\mathrm{C}$ por varias razones, pues es muy difícil hacer el diagnóstico en la población y las pruebas disponibles son costosas.

\section{Conclusión}

Dr. Roberto León: la determinación genotípica es una herramienta útil para el manejo de la hepatitis C. Desde el punto de vista clínico, es importante hacerlo al tomar la decisión de tratar a un paciente, ya que el genotipo determina de manera dramática la duración del tratamiento y la respuesta al mismo. La alternativa del serotipo es válida, pues resulta más económica, más sencilla técnicamente y diferencia el genotipo 1 de los restantes, con exactitud.

En cuanto a la epidemiología de la hepatitis $\mathrm{C}$ en Colombia, parece que se acerca mucho a la inciden- 
cia de la mayoría de los países latinoamericanos, inclusive a la de Estados Unidos aunque llama la atención que las formas de transmisión son bastantes distintas entre nuestras naciones y los países de América del Norte.

Evidentemente hay grupos poblacionales de alto riesgo, como aquellos expuestos a transfusiones periódicas, los sujetos en diálisis, los hemofílicos y las personas que han recibido transfusiones de sangre antes de 1993. Resultaría conveniente tratar de localizar a los sujetos transfundidos antes de 1993, para practicarles las pruebas diagnós-ticas correspondientes. Por supuesto, hacen falta estudios de otras formas de transmisión, como los tatuajes, los procedimientos de piercing, etcétera y orientar a la población a cerca de no someterse a estas prácticas de riesgo o hacerlo bajo condiciones máximas de asepsia.

En cuanto a la historia natural del virus $\mathrm{C}$ y las pruebas diagnósticas, es significativo que en Colombia hasta $85 \%$ de los infectados hacen una infección crónica y de ellos, $30 \%$ a $40 \%$ evolucionan a hepatitis crónica y deberían recibir tratamiento. Sin embargo, no existe un indicador confiable que permita distinguir a los sujetos con hepatitis crónica que van a evolucionar desfavorablemente, aunque parece ser que aquellos con muy poca hepatitis pueden permanecer estables y, en consecuencia, no necesitarían tratamiento.

Con respecto a la parte de pruebas diagnósticas, es importante destacar el papel de los estudios de biología molecular, los cuales son estándar hoy en día en el manejo de la hepatitis $\mathrm{C}$.

En pacientes candidatos a tratamiento, además de hacer el PCR cualitativo, hay que realizar el PCR cuantitativo, es decir, medir la viremia, lo cual tiene un valor pronóstico y contribuye a establecer la duración del tratamiento. El papel del RIBA es cuestionado y su utilidad práctica radica en diferenciar los verdaderos positivos de los falsos positivos; pero más allá de esta cuestión académica o epidemiológica, en el manejo clínico no hace una mayor diferencia. El tratamiento más recomendado hoy, en pacientes sin contraindicación específica, es la terapia combinada con interferón alfa 2B (a dosis de tres millones de unidades tres veces por semana por vía subcutánea) y ribavirina (a dosis entre 1.000 y 1.200 $\mathrm{mg} /$ día, según el peso del paciente). No obstante, muchos pacientes no van a responder y por eso es fundamental continuar explorando nuevas opciones terapéuticas.

Finalmente, en la parte de prevención de la hepatitis $\mathrm{C}$, resulta clara la importancia del tamizaje en los bancos de sangre para evitar la principal fuente de diseminación de la enfermedad, que son las transfusiones con sangre contaminada. Además, es fundamental promover la educación dirigida a la comunidad acerca de temas tales como los factores de riesgo y los tratamientos disponibles en la actualidad, para no alarmar innecesariamente a la población.

\section{Conferencistas}

Dr. Raúl Edmundo Piña Tellez

Gastroenterólogo,

Jefe del Servicio de Gastroenterología-Hospital Central de la Policía, Bogotá.

Dr. Rolando Ortega

Internista-Gastroenterólogo, Clínica Enrique de La Vega ISS, Cartagena.

Dr. Roberto León

Hepatólogo, Caracas, Venezuela.

Dra. Gladys Espinosa

Bacterióloga-Epidemióloga, Secretaría Distrital de Salud, Bogotá.

Dr. Enrique Ponce de León

Gastroenterólogo, Bucaramanga.

Dr. Mauricio Beltrán

Bacteriólogo-Epidemiólogo, Instituto Nacional de Salud, Bogotá.

Dr. Julián Martínez

Coordinador Unidad de Gastroenterología-Hospital Universitario de la Samaritana, Bogotá.

Dr. Rafael Claudino Botero

Hepatólogo, Fundación Cardio-Infantil, Bogotá.

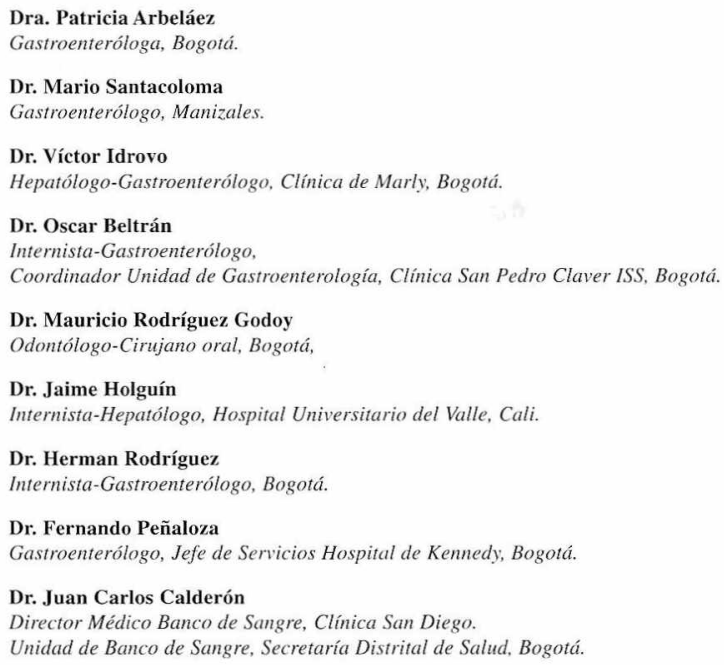

